\title{
Antecedent North Pacific Jet Regimes Conducive to the Development of Continental U.S. Extreme Temperature Events during the Cool Season
}

\author{
ANDrew C. Winters, LANCE F. Bosart, AND DANiEl Keyser \\ Department of Atmospheric and Environmental Sciences, University at Albany, State University of New York, Albany, New York
}

(Manuscript received 27 September 2018, in final form 6 February 2019)

\begin{abstract}
This study considers the development of continental U.S. extreme temperature events (ETEs) during the cool season (September-May), where extreme temperatures are defined in terms of percentiles and events are defined in terms of the spatial coverage of extreme temperatures. Following their identification, ETEs are classified into geographic clusters and stratified based on the state of the North Pacific jet (NPJ) stream prior to ETE initiation using an NPJ phase diagram. The NPJ phase diagram is developed from the two leading modes of NPJ variability during the cool season. The first mode corresponds to a zonal extension or retraction of the exit region of the climatological NPJ, while the second mode corresponds to a poleward or equatorward shift of the exit region of the climatological NPJ. The projection of $250-\mathrm{hPa}$ zonal wind anomalies onto the NPJ phase diagram prior to ETEs demonstrates that the preferred state and evolution of the NPJ prior to ETEs varies considerably based on the geographic location of ETE initiation and the season. Southern plains extreme warm events are an exception, however, since extreme warm events in that location most frequently initiate following a retracted NPJ during all seasons. The NPJ phase diagram is subsequently utilized to examine a synoptic-scale flow evolution highly conducive to the initiation of southern plains extreme warm events via composite analysis. The composite analysis demonstrates that a retracted NPJ supports an amplification of the upper-tropospheric flow pattern over North America, which then induces persistent lowertropospheric warm-air advection over the southern plains prior to ETE initiation.
\end{abstract}

\section{Introduction}

The occurrence of extreme temperature events (ETEs) during the cool season (September-May) is often accompanied by considerable societal and economic impacts. Extreme cold events, in particular, are responsible for about 30 deaths per year in the United States (NWS 2018), can result in substantial damage to infrastructure (e.g., Cellitti et al. 2006), and can induce agricultural and economic losses (e.g., Rogers and Rohli 1991; Gu et al. 2008; Dole et al. 2014; Wolter et al. 2015). While extreme warm events during the cool season have received comparatively less consideration within the refereed literature, they also pose considerable risks. These risks include the development of floods and ice jams on waterways due to rapid snow and ice melt (e.g., Westby et al. 2013), economic losses for industries reliant upon wintry conditions (e.g., Westby et al. 2013), and the potential loss of early season agricultural products when an extreme warm event is followed by a hard

Corresponding author: Andrew C. Winters, acwinters@albany.edu freeze (e.g., Rogers and Rohli 1991; Gu et al. 2008; Westby et al. 2013; Dole et al. 2014; Peterson and Abatzoglou 2014; Westby and Black 2015).

From a climatological perspective, the development of one or several ETEs during a single season can contribute disproportionately to temperature anomaly statistics for that particular season (e.g., Hoerling et al. 2013; Peterson et al. 2013; Dole et al. 2014; Hartmann 2015; Wolter et al. 2015). The disproportionate contribution of ETEs to seasonal temperature anomaly statistics suggests that ETEs need to be considered in order to understand the dynamical and thermodynamic processes that operate at the weather-climate intersection. Such investigations of ETEs are of additional importance given projected changes in the frequency of ETEs within future climates (e.g., Walsh et al. 2001; Meehl and Tebaldi 2004; Portis et al. 2006; Vavrus et al. 2006; Peterson et al. 2013; Westby et al. 2013; Scherer and Diffenbaugh 2014; Grotjahn et al. 2016).

Numerous studies have sought relationships between cool season ETEs over North America and modes of intraannual climate variability as part of an effort to 
TABLE 1. Modes of intraannual and interannual climate variability and selected studies that have sought relationships between these modes of variability and cool season ETEs.

\begin{tabular}{ll}
\hline \hline \multicolumn{1}{c}{ Modes of climate variability } & \multicolumn{1}{c}{ Citations } \\
\hline Pacific-North American pattern & $\begin{array}{c}\text { Rogers and Rohli (1991); Downton and Miller (1993); Cellitti et al. (2006); Westby et al. (2013); } \\
\text { Loikith and Broccoli (2014); Westby and Black (2015) } \\
\text { Downton and Miller (1993); Cellitti et al. (2006); Kenyon and Hegerl (2008); Guirguis et al. (2011); } \\
\text { Nerth Atlantic Oscillation }\end{array}$ \\
$\begin{array}{l}\text { Wiggins et al. (2002); Lim and Schubert (2011); Loikith and Broccoli (2014) } \\
\text { Arctic Oscillation }\end{array}$ & Matsueda and Takaya (2015); Zhang (2016); Roundy et al. (2017) \\
Madden-Julian oscillation & Guirguis et al. (2011); Westby et al. (2013); Xie et al. (2017) \\
Pacific decadal oscillation & Namias (1978); Higgins et al. (2002); Carrera et al. (2004); Meehl et al. (2007); Kenyon and Hegerl \\
El Niño-Southern Oscillation & (2008); Guirguis et al. (2011); Lim and Schubert (2011); Westby et al. (2013); Loikith and \\
& Broccoli (2014); Xie et al. (2017) \\
\hline
\end{tabular}

understand the large-scale meteorological patterns associated with the development of ETEs (Table 1). For example, prior work has identified relationships between ETEs and the phase of the Pacific-North American pattern (PNA), the North Atlantic Oscillation (NAO), the Arctic Oscillation (AO), and the Madden-Julian oscillation (MJO). Cool season ETEs have also been related to modes of interannual climate variability such as the phase of the Pacific decadal oscillation (PDO) and El Niño-Southern Oscillation (ENSO). Subseasonal and seasonal forecasts of ETEs, in particular, benefit considerably from knowledge of these relationships.

In addition to intraannual and interannual modes of climate variability, Loikith and Broccoli (2014) emphasize that the synoptic-scale flow pattern plays an important role in the development of ETEs, especially during the boreal winter. In particular, regional case studies and composite analyses of cool season ETEs over North America have identified attributes of the synoptic-scale flow pattern that are often associated with the development of ETEs. Common attributes among these studies include an amplified upper-tropospheric flow pattern over North America (e.g., Dallavalle and Bosart 1975; Hartjenstein and Bleck 1991; Colle and Mass 1995; Konrad 1996; Cellitti et al. 2006; Loikith and Broccoli 2012; Westby and Black 2015; Xie et al. 2017), the development of surface cyclones and anticyclones that facilitate the transport of anomalous cold or warm air into a region (e.g., Dallavalle and Bosart 1975; Colucci and Davenport 1987; Konrad and Colucci 1989; Colle and Mass 1995; Konrad 1996; Walsh et al. 2001; Westby and Black 2015; Grotjahn and Zhang 2017; Xie et al. 2017), and topographical processes such as cold-air damming (e.g., Bell and Bosart 1988; Hartjenstein and Bleck 1991; Colle and Mass 1995) and the adiabatic warming of air parcels induced by lee subsidence (e.g., Brewer et al. 2012, 2013). Thermodynamic factors such as antecedent precipitation and soil moisture (e.g., Turner and Gyakum
2011; Brewer et al. 2013; Hoerling et al. 2013; Dole et al. 2014), as well as adiabatic and diabatic processes occurring along air parcel trajectories in the absence of topography (e.g., Konrad and Colucci 1989; Walsh et al. 2001; Portis et al. 2006; Turner and Gyakum 2011) can also contribute to the development of ETEs.

While the synoptic-scale flow patterns associated with cool season ETEs feature common attributes, it is apparent that the structure and evolution of these flow patterns are highly dependent on the geographic location of the ETE and the meteorological season (e.g., Loikith and Broccoli 2012, 2014; Westby et al. 2013; Westby and Black 2015; Grotjahn et al. 2016; Grotjahn and Zhang 2017; Loikith et al. 2017; Xie et al. 2017). On the basis of these relationships, Grotjahn et al. (2016) recommend in their review of large-scale meteorological patterns associated with ETEs that additional work be conducted 1) to determine whether more than one type of largescale meteorological flow pattern is conducive to the development of ETEs in a particular geographic location, and 2) to increase understanding of the synopticdynamic mechanisms that support the development of large-scale meteorological flow patterns associated with ETEs. These two recommendations motivate the present study.

Case studies of extreme weather events (EWEs) over North America demonstrate that the state and evolution of the North Pacific jet (NPJ) stream can support the establishment of a downstream environment that is conducive to EWEs (e.g., Cordeira and Bosart 2010; Bosart et al. 2017). Consequently, the present study addresses the two recommendations from Grotjahn et al. (2016) by adopting an objective NPJ-centered framework to determine the configurations of the NPJ, or NPJ regimes, that are conducive to the development of continental U.S. ETEs during the cool season. The adoption of this framework permits an examination of the degree to which the preferred NPJ configurations prior to ETEs differ depending on both the geographic 
location of the ETE within the continental United States and the meteorological season.

The remainder of this manuscript is structured as follows. Section 2 introduces an identification scheme for continental U.S. ETEs as well as an NPJ phase diagram that will be used to characterize the state and evolution of the NPJ prior to the development of ETEs during the cool season. Section 3 discusses the characteristics of the NPJ prior to the development of continental U.S. ETEs during the cool season employing the NPJ phase diagram. Section 4 provides an illustrative example demonstrating how the NPJ phase diagram can be utilized to examine a synoptic-scale flow evolution that is highly conducive to the development of southern plains extreme warm events. Section 5 offers a discussion of the results from previous sections and the implications those results may have for operational forecasts of ETEs.

\section{Methodology}

\section{a. ETE identification scheme}

Given that analyses of 2-m temperature are not available from the National Centers for Environmental Prediction Climate Forecast System Reanalysis (CFSR; Saha et al. 2010, 2014), this study utilizes 1 -h forecasts ${ }^{1}$ of 2-m temperature from the CFSR during the 36-yr period, 1979-2014. The 1-h forecasts of 2-m temperature from the CFSR are $0.5^{\circ}$ resolution, are initialized every $6 \mathrm{~h}$ at the standard analysis times (i.e., 0000, 0600, 1200, and 1800 UTC), and represent a uniformly gridded and temporally continuous dataset of 2-m temperatures that is suitable for identifying continental U.S. ETEs during the period of study. The discussion that follows outlines the ETE identification scheme with respect to continental U.S. extreme warm events. Adaptations to the ETE identification scheme are then described in order to identify continental U.S. extreme cold events.

To identify extreme warm events, 2-m temperature distributions are constructed for each grid point at every forecast verification time during the year (i.e., 4 times daily at 0100, 0700, 1300, and 1900 UTC). A 2-m temperature distribution is constructed for a grid point at a single verification time by isolating the 2-m temperatures for that grid point at 24-h intervals within a 21-day window centered on the verification time for every year between 1979 and 2014. A sample 2-m temperature distribution for the 21-day window centered on

\footnotetext{
${ }^{1}$ The 0 -h forecasts of $2-\mathrm{m}$ temperature are available from NCEI, however, these grids represent the spin-up of the CFSR forecast and are not recommended for use (UCAR 2018).
}

1900 UTC 30 May during 1979-2014 is provided in Fig. 1a for a grid point near Albany, New York.

The 2-m temperature distributions are then utilized to objectively define thresholds for extreme warmth that are specific to each grid point at a particular verification time. Extreme warm temperatures are defined in the present study as those temperatures that are greater than the 99th percentile temperature for a grid point at a particular verification time. For the 2-m temperature distribution constructed for a grid point near Albany the 99th percentile temperature is $32^{\circ} \mathrm{C}\left(90^{\circ} \mathrm{F}\right)$ at $1900 \mathrm{UTC}$ 30 May (Fig. 1a). A horizontal distribution of the 99th percentile temperature at 1900 UTC 30 May highlights the degree to which the 99th percentile temperature can vary as a function of orography and proximity to bodies of water (Fig. 1b).

To ensure that the ETE identification scheme captures areas of extreme warmth that are concentrated within the same geographic region, the continental United States is split into two domains to the east and west of $105^{\circ} \mathrm{W},{ }^{2}$ respectively (Fig. 1b). For each domain, 1-h forecasts of 2-m temperature that exhibit at least one grid point over land with a temperature greater than its respective 99th percentile temperature are cataloged. The cataloged 1-h forecasts within each domain are subsequently ranked according to the number of grid points with temperatures greater than their respective 99th percentile temperatures. Those 1 -h forecasts that rank in the top 5\% in terms of the number of grid points exhibiting extreme warmth are isolated and labeled as extreme warm events within that spatial domain. For example, at least 224 grid points must exhibit temperatures greater than their respective 99th percentile temperatures in order for a particular 1-h forecast to qualify as an extreme warm event within the eastern U.S. domain (Fig. 1c). By imposing a minimum gridpoint threshold, the identification scheme ensures that ETEs are extreme not only with respect to temperature but also the spatial extent of extreme temperature.

Last, extreme warm events that occurred within $24 \mathrm{~h}$ of another extreme warm event are considered to be the same event, and all events are subsequently classified based on the meteorological season [i.e., fall (September-November), winter (December-February), spring (March-May), summer (June-August)] at the time of event initiation. The identification scheme for extreme warm events yields 304 and 264 extreme warm

\footnotetext{
${ }^{2}$ Longitude $105^{\circ} \mathrm{W}$ is chosen given that it parallels the easternmost extent of the Rocky Mountains, which serve as a natural geographic barrier suitable for partitioning the continental United States.
} 

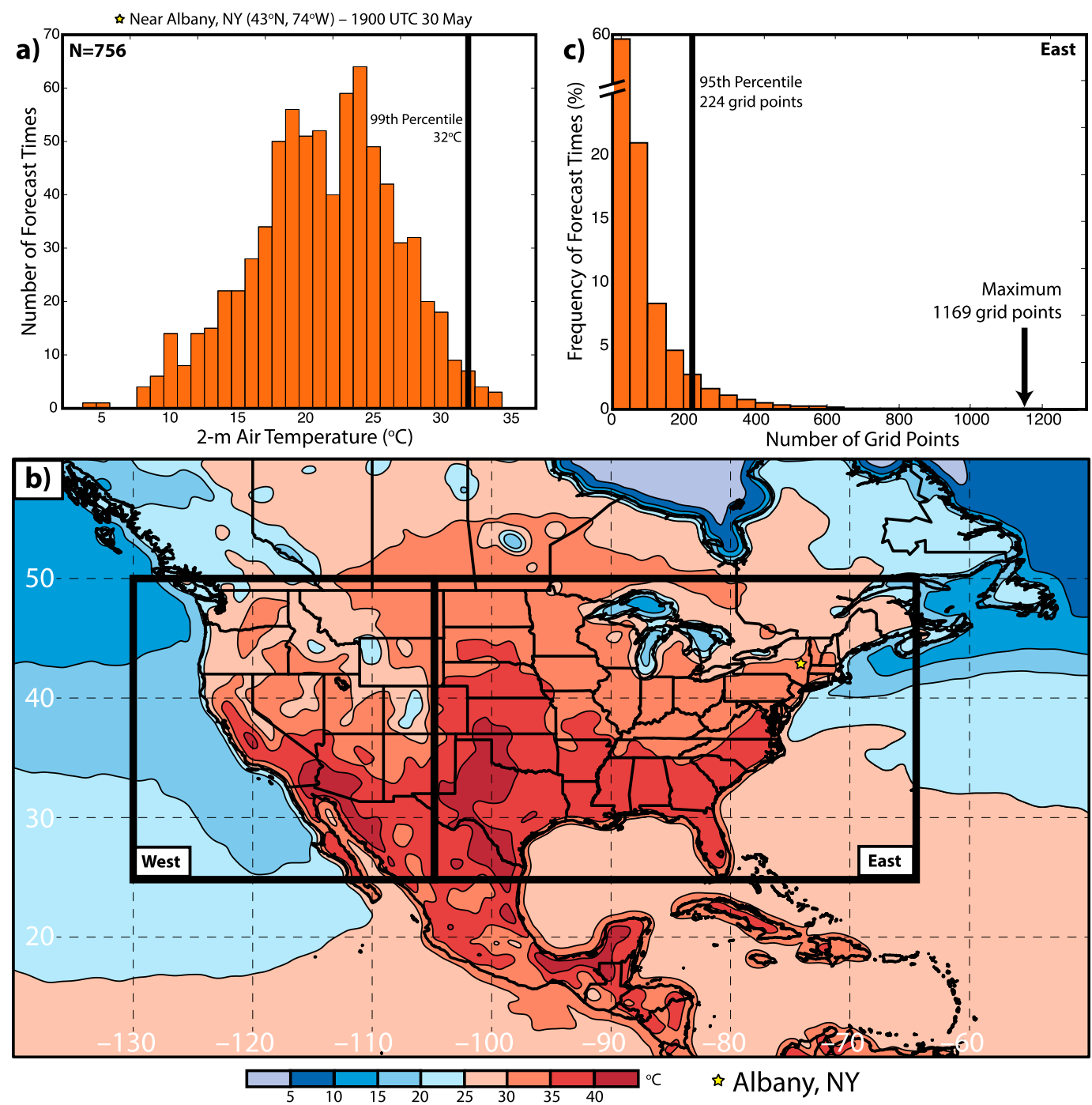

FIG. 1. (a) Frequency distribution of 2-m temperatures compiled at 24-h intervals within a 21-day window centered on 1900 UTC 30 May for every year between 1979 and 2014 for a grid point near Albany, NY (43N, $\left.74^{\circ} \mathrm{W}\right)$. The vertical black bar identifies the 99 th percentile temperature of the distribution, and the quantity in the top left of the panel indicates the total number of 1-h forecasts that are used to construct the distribution. (b) The 99th percentile temperature at 1900 UTC 30 May is shaded in the fill pattern. The black boxes identify the eastern and western U.S. domains used to identify continental U.S. ETEs. (c) Frequency distribution of the number of grid points characterized by extreme warmth within the subset of 1-h forecasts during 1979-2014 that exhibit at least one grid point over land in the eastern U.S. domain with a 2-m temperature greater than its respective 99th percentile temperature. The vertical black bar identifies the number of grid points corresponding to the 95 th percentile of the distribution. The black arrow identifies the maximum number of grid points characterized by extreme warmth in a single 1-h forecast during 1979-2014.

events during 1979-2014 within the eastern and western U.S. domains, respectively (Table 2). An analogous scheme is employed to identify continental U.S. extreme cold events by cataloging 1-h forecasts of 2-m temperature with grid points that exhibit temperatures less than their respective 1st percentile temperatures. The identification scheme yields 225 and 269 extreme cold events during 1979-2014 within the eastern and western U.S. domains, respectively (Table 2). The identified ETEs are subsequently filtered to retain only cool season ETEs (Table 2) for the forthcoming analysis in sections 3 and 4.

Frequency distributions indicating where extreme warm events initiate within the eastern and western U.S. domains during the cool season are shown in Figs. $2 a$ and $2 b$, respectively, along with the individual 
TABLE 2. The characteristics of continental U.S. ETEs identified during the 36-yr period, 1979-2014. The characteristics provided include the minimum gridpoint thresholds required for the identification of an ETE within the eastern and western U.S. domains, the total number of ETEs identified within the eastern and western U.S. domains, and the number of ETEs that occurred during the cool season. Refer to the text for a full discussion of the ETE identification scheme.

\begin{tabular}{lcccc}
\hline \hline & $\begin{array}{c}\text { Spatial } \\
\text { domain }\end{array}$ & $\begin{array}{c}\text { Min } \\
\text { gridpoint } \\
\text { threshold }\end{array}$ & $\begin{array}{c}\text { Total No. of } \\
\text { identified } \\
\text { events }\end{array}$ & $\begin{array}{c}\text { Cool } \\
\text { season } \\
\text { events }\end{array}$ \\
\hline Extreme warm events & East & 224 & 304 & 239 \\
& West & 144 & 264 & 204 \\
Extreme cold events & East & 221 & 225 & 173 \\
& West & 125 & 269 & 196 \\
\hline
\end{tabular}

event centroids of every extreme warm event at the time of event initiation. The centroid for an individual extreme warm event at the time of event initiation is determined by calculating a weighted average of the latitude and longitude of every grid point that exhibited a temperature greater than its respective 99th percentile temperature. In calculating the weighted average, the latitude and longitude at every qualifying grid point is multiplied by the magnitude of the difference between the temperature at the grid point and the 99th percentile temperature for the grid point. Consequently, an event centroid is focused on those grid points where temperatures exceed their respective 99th percentile temperatures by the largest magnitudes.

A frequency maximum in eastern U.S. extreme warm event initiation is observed in the northern plains, with a secondary maximum extending from the central and southern plains eastward toward the southern Mississippi River valley (Fig. 2a). Extreme warm events that impact the U.S. East Coast during their lifespan often initiate upstream over the central United States before progressing eastward, which may contribute to the lower frequency of extreme warm event initiation observed near the U.S. East Coast compared to locations farther upstream. To investigate whether the NPJ regimes that most frequently precede extreme warm event initiation differ based on the location of event initiation, $k$-means clustering is used to classify the eastern U.S. extreme warm event centroids into three geographic clusters $^{3}$ : the "Northern Plains," "Southern Plains,"

\footnotetext{
${ }^{3}$ The number of clusters must be specified a priori when employing $k$-means clustering. Several numbers of clusters were tested to determine the number of clusters that most effectively represent the frequency distributions shown in Figs. 2 and 3 and that objectively classify events into subsets that are geographically meaningful.
}

and "East Coast". The event centroids shown in Fig. 2a are colored based on their respective geographic cluster and match favorably with those locations that exhibit relative maxima in extreme warm event initiation. The frequency distribution for western U.S. extreme warm event initiation features two primary maxima located in the Pacific Northwest and in the northern U.S. Rocky Mountains, respectively, and a secondary maximum in the southwestern United States (Fig. 2b). As for eastern U.S. extreme warm events, $k$-means clustering is used to classify the western U.S. extreme warm event centroids into three geographic clusters: the "Pacific Northwest," "Northern Rockies," and "Southwest".

Frequency distributions indicating where extreme cold events initiate within the eastern and western U.S. domains during the cool season are shown in Figs. 3a and $3 b$, respectively. Eastern U.S. extreme cold events most frequently initiate in the Northern and Southern Plains, with relative maxima also observed in the northeastern Great Lakes region and the middle Mississippi River valley (Fig. 3a). In contrast to eastern U.S. extreme warm events, four geographic clusters are required in order to classify the extreme cold event centroids in a manner consistent with those locations that experience the highest frequency of extreme cold event initiation: the "Northern Plains," "Northeast," "Southern Plains," and "Southeast". For western U.S. extreme cold event initiation, a frequency maximum is observed in the northern U.S. Rocky Mountains, with a secondary maximum extending along the U.S. West Coast and into the southwestern United States (Fig. 3b). As for western U.S. extreme warm events, the western U.S. extreme cold event centroids are classified into three geographic clusters: the "Pacific Northwest," "Northern Rockies," and "Southwest".

\section{b. The NPJ phase diagram}

The NPJ regimes that precede continental U.S. ETEs are determined using an NPJ phase diagram introduced by Winters et al. (2019) that is developed from the two leading modes of $250-\mathrm{hPa}$ zonal wind variability over the North Pacific during the cool season. Griffin and Martin (2017) and Winters et al. (2019) demonstrate that knowledge of the prevailing NPJ regime derived from the NPJ phase diagram offers considerable value to operational medium-range (6-10 day) and week two (8-14 day) forecasts of temperature over the continental United States. Consequently, given its operational utility, the NPJ phase diagram represents an objective tool that is well suited to examine the antecedent large-scale environments associated with continental U.S. ETEs.

The discussion in this subsection is adapted from Winters et al. (2019) and is presented here given its 

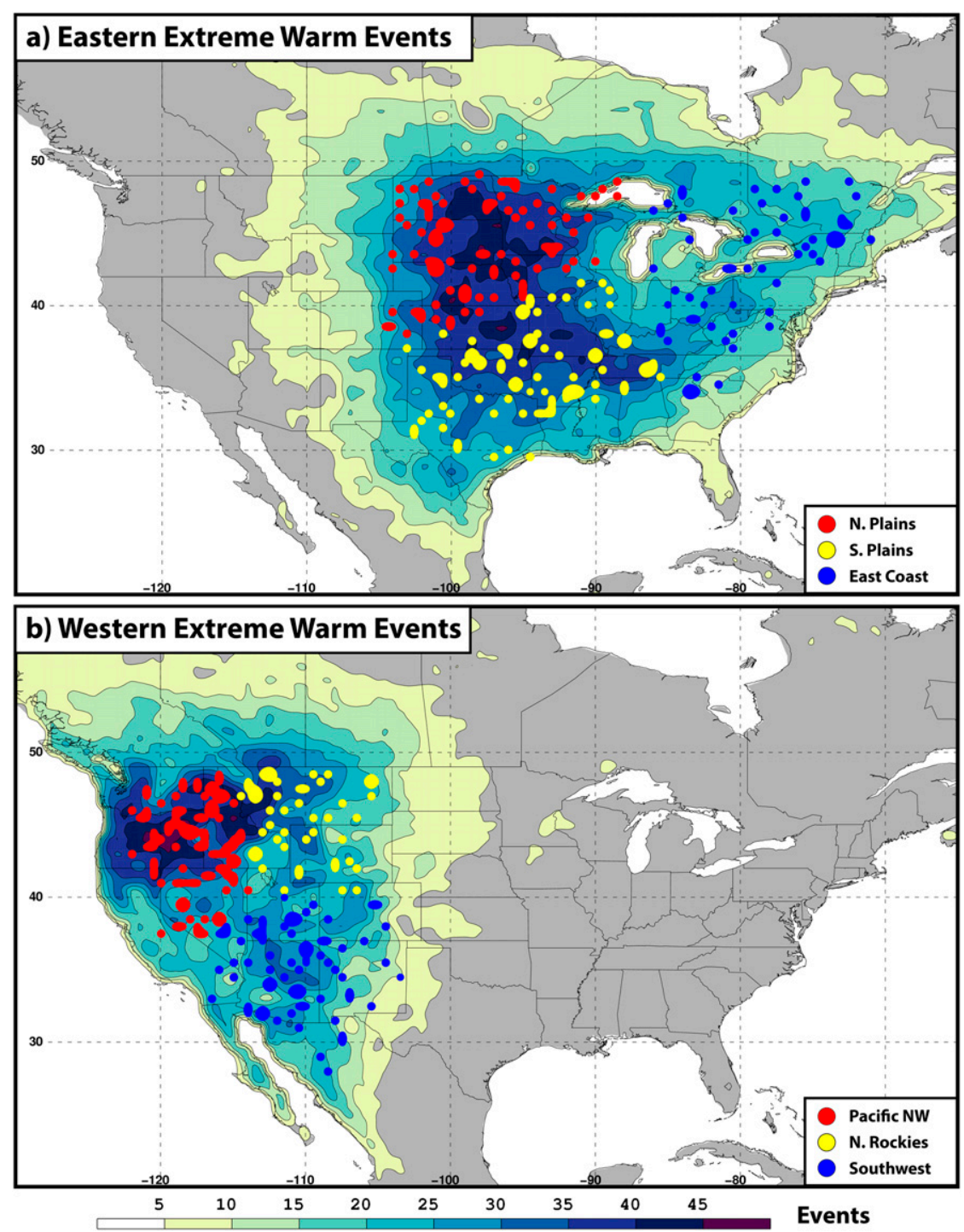

FIG. 2. (a) The number of eastern U.S. extreme warm events during the cool season that initiate at each grid point is shaded in the fill pattern. Individual extreme warm event centroids are represented by dots and are colored according to their respective geographic cluster. (b) As in (a), but for extreme warm events that initiate within the western U.S. domain during the cool season.

relevance to the current study. The NPJ phase diagram is developed utilizing 250 -hPa zonal wind anomalies from the CFSR at every 6-h analysis time during 1979-2014 excluding the summer months (June-August). Anomalies are calculated as the deviation of the instantaneous 250-hPa zonal wind from a 21-day running mean centered on each analysis time in order to remove the 36-yr mean as well as the annual and diurnal cycles. The 21-day running mean at a particular analysis time is calculated from $250-\mathrm{hPa}$ zonal wind data taken at 24-h intervals within a 21-day window centered on the analysis time for every year between 1979 and 2014.
A traditional empirical orthogonal function (EOF) analysis (Wilks 2011, chapter 12) is subsequently performed on the 250-hPa zonal wind anomaly data within a horizontal domain bounded in latitude from $10^{\circ}$ to $80^{\circ} \mathrm{N}$ and in longitude from $100^{\circ} \mathrm{E}$ to $120^{\circ} \mathrm{W}$ in order to encompass the upper-tropospheric flow pattern over the North Pacific basin and to determine the two leading modes of NPJ variability.

The regression of $250-\mathrm{hPa}$ zonal wind anomaly data onto the first two standardized principal components (PC 1 and PC 2) obtained from the traditional EOF analysis reveals the spatial structures of EOF 1 and EOF 

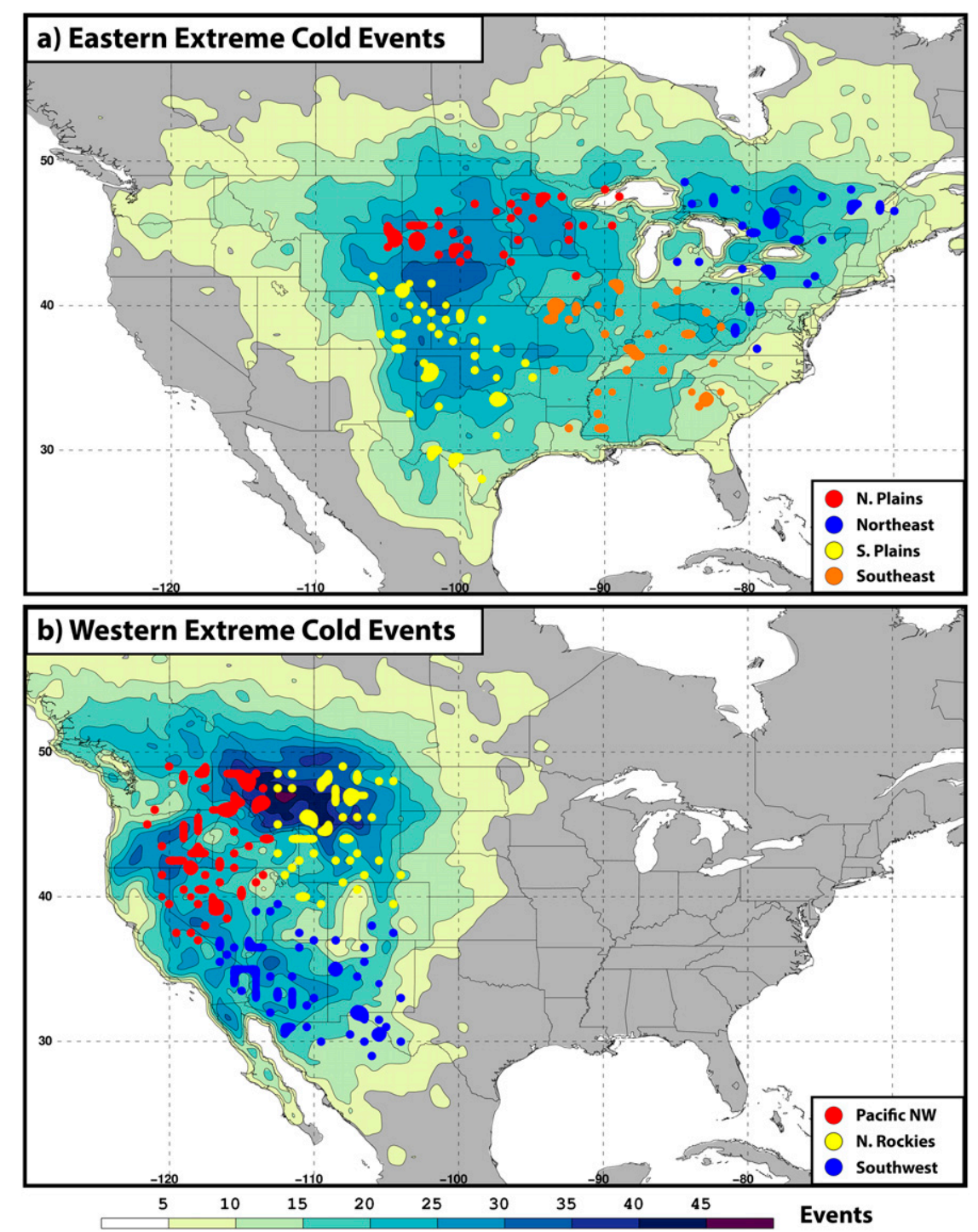

FIG. 3. As in Fig. 2, but for extreme cold events that initiate within the (a) eastern U.S. domain and (b) western U.S. domain during the cool season.

2 (Figs. 4a,b, respectively). EOF 1 accounts for $10.3 \%$ of the variance of the $250-\mathrm{hPa}$ zonal wind over the North Pacific during the cool season and corresponds to longitudinal variability of the $250-\mathrm{hPa}$ zonal wind in the vicinity of the exit region of the climatological NPJ. A positive EOF 1 pattern is associated with a zonal extension of the exit region of the climatological NPJ (i.e., a jet extension), while a negative EOF 1 pattern is associated with a retraction of the exit region of the climatological NPJ (i.e., a jet retraction). EOF 2 accounts for $7.8 \%$ of the variance of the $250-\mathrm{hPa}$ zonal wind over the North Pacific during the cool season and corresponds to latitudinal variability of the $250-\mathrm{hPa}$ zonal wind in the vicinity of the exit region of the climatological NPJ. A positive EOF 2 pattern is associated with a poleward shift of the exit region of the climatological NPJ (i.e., a poleward shift), while a negative EOF 2 pattern is associated with an equatorward shift of the exit region of the climatological NPJ (i.e., an equatorward shift).

The EOF patterns and the combined variance that EOF 1 and EOF 2 account for are comparable to that found in previous studies of NPJ variability (Athanasiadis et al. 2010; Jaffe et al. 2011; Griffin and Martin 2017), and the two leading EOFs are statistically well separated using the methodology outlined in North et al. (1982). Furthermore, the combined variance that EOF 1 and EOF 2 account for is comparable to the variance accounted for by well-established atmospheric teleconnection patterns, such as in Wheeler and Hendon (2004) for 

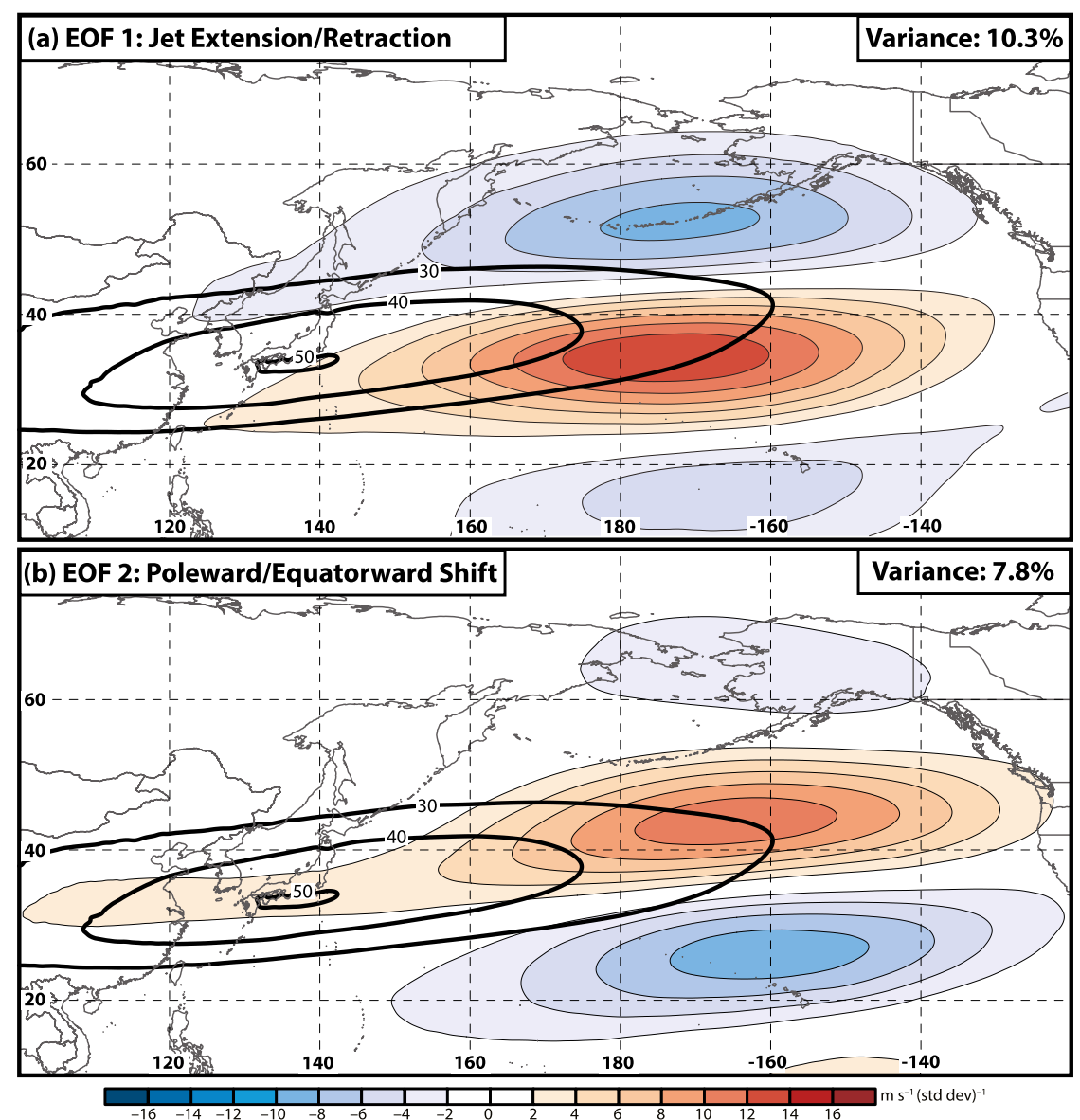

FIG. 4. (a) September-May 250-hPa mean zonal wind is contoured in black every $10 \mathrm{~m} \mathrm{~s}^{-1}$ above $30 \mathrm{~m} \mathrm{~s}^{-1}$ and the regression of 250-hPa zonal wind anomaly data onto standardized PC 1 (i.e., EOF 1) is shaded $\left(\mathrm{m} \mathrm{s}^{-1}\right)$. The variance of $250-\mathrm{hPa}$ zonal wind during the cool season that EOF 1 accounts for is listed in the top right of the panel. (b) As in (a), but for the regression of 250-hPa zonal wind anomaly data onto standardized PC 2 (i.e., EOF 2). Figure and caption from Winters et al. (2019).

the MJO, Barnston and Livezey (1987) for the PNA and the NAO, and Thompson and Wallace (1998) for the AO.

The magnitudes and signs of PC 1 and PC 2 are normalized to unit variance, and time series constructed from the instantaneous PCs assist in characterizing the temporal evolution of the NPJ with respect to EOF 1 and EOF 2. The use of instantaneous PCs produces a noisy time series, however, due to the high-frequency variability that characterizes the NPJ on daily time scales (e.g., Griffin and Martin 2017, their Fig. 1). Consequently, the instantaneous PCs are smoothed through the calculation of a weighted average of the instantaneous PCs within $\pm 24 \mathrm{~h}$ of each analysis time $t_{0}$. The weight $w$ applied to the instantaneous PCs at each analysis time $t$ within $\pm 24 \mathrm{~h}$ of $t_{0}$ is defined as $w=$ $5-\left|t-t_{0}\right| / 6$, for $\left|t-t_{0}\right| \leq 24 \mathrm{~h}$.

The weighted PCs at a particular analysis time can be plotted on a two-dimensional Cartesian grid (i.e., the
NPJ phase diagram) in an effort to visualize the state of the NPJ and to define the prevailing NPJ regime (Fig. 5). The position along the abscissa (ordinate) within the NPJ phase diagram corresponds to the value of weighted PC 1 (weighted PC 2) and indicates how strongly the 250-hPa zonal wind anomalies project onto EOF 1 (EOF 2). It is important to note that the uppertropospheric flow pattern over the North Pacific at any particular time is more complex than that suggested by the NPJ phase diagram. Nevertheless, given that the NPJ phase diagram is constructed from the two leading modes of 250-hPa zonal wind variability over the North Pacific, plotting the weighted PCs in the NPJ phase diagram and tracking their evolution over time encompasses many important aspects of the NPJ evolution.

As demonstrated extensively in prior work (e.g., Athanasiadis et al. 2010; Jaffe et al. 2011; Griffin and Martin 2017; Winters et al. 2019), each NPJ regime 


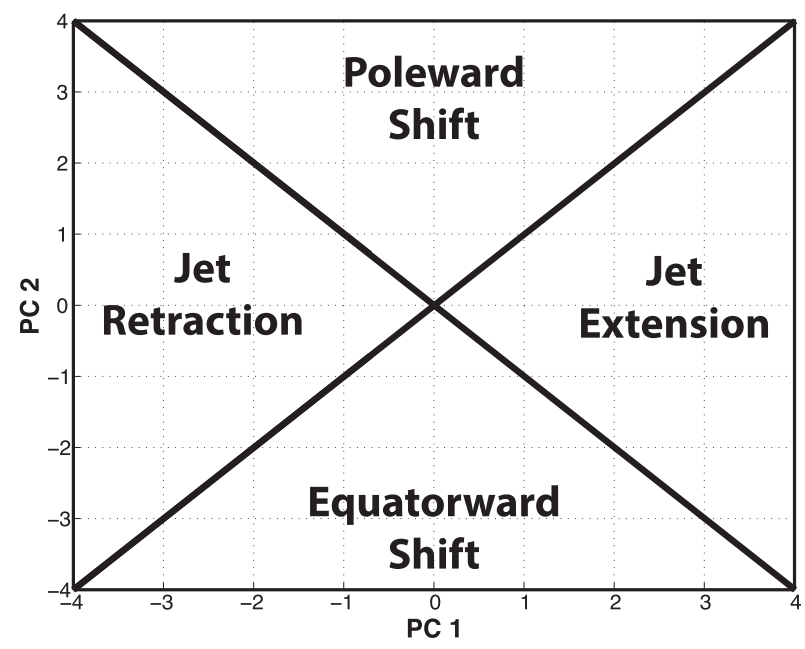

FIG. 5. Schematic illustrating the NPJ phase diagram and the classification scheme used to determine the NPJ regime prior to ETE initiation. The values plotted on the axes of the NPJ phase diagram correspond to the value of weighted PC 1 and weighted PC 2 , respectively.

exhibits a strong influence on the character of the downstream large-scale flow pattern over North America. To illustrate this influence, the weighted PCs are calculated for all analysis times in the CFSR during 1979-2014, excluding the summer months, and are subsequently classified into NPJ regimes according to Fig. 5. As in Winters et al. (2019), periods during which the NPJ is a Euclidean distance of at least 1 standard deviation from the origin of the NPJ phase diagram and characterized by the same NPJ regime for at least three consecutive days are isolated for composite analysis. Composite analyses of the upper- and lower-tropospheric flow patterns (Figs. 6 and 7, respectively) 4 days following the initiation of each NPJ regime describe the characteristic structure of the NPJ associated with each NPJ regime, as well as the relationship between each NPJ regime and lowertropospheric temperatures over North America.

A jet extension features a strong, zonally oriented NPJ that extends toward the U.S. West Coast (Fig. 6a) and is associated with above- and below-normal temperatures over western and eastern North America, respectively (Fig. 7a). A jet retraction is characterized by an anomalous upper-tropospheric ridge over the central North Pacific that is associated with a retracted NPJ over the western North Pacific and a split NPJ to the east of the date line (Fig. 6b). Jet retractions are associated with below-normal temperatures along the west coast of North America and above-normal temperatures in parts of the Southern Plains and Ohio River valley (Fig. 7b). A poleward shift is characterized by a strong NPJ whose exit region is deflected poleward toward the Pacific Northwest (Fig. 6c), as well as above-normal temperatures across northern North America (Fig. 7c). Last, an equatorward shift is associated with an anomalous upper-tropospheric ridge over the high-latitude North Pacific and an anomalous trough over the subtropical North Pacific, reminiscent of a Rex block (Rex 1950), that results in an equatorward deflection of the NPJ (Fig. 6d). Below-normal temperatures are observed across northern North America in conjunction with an equatorward shift (Fig. 7d).

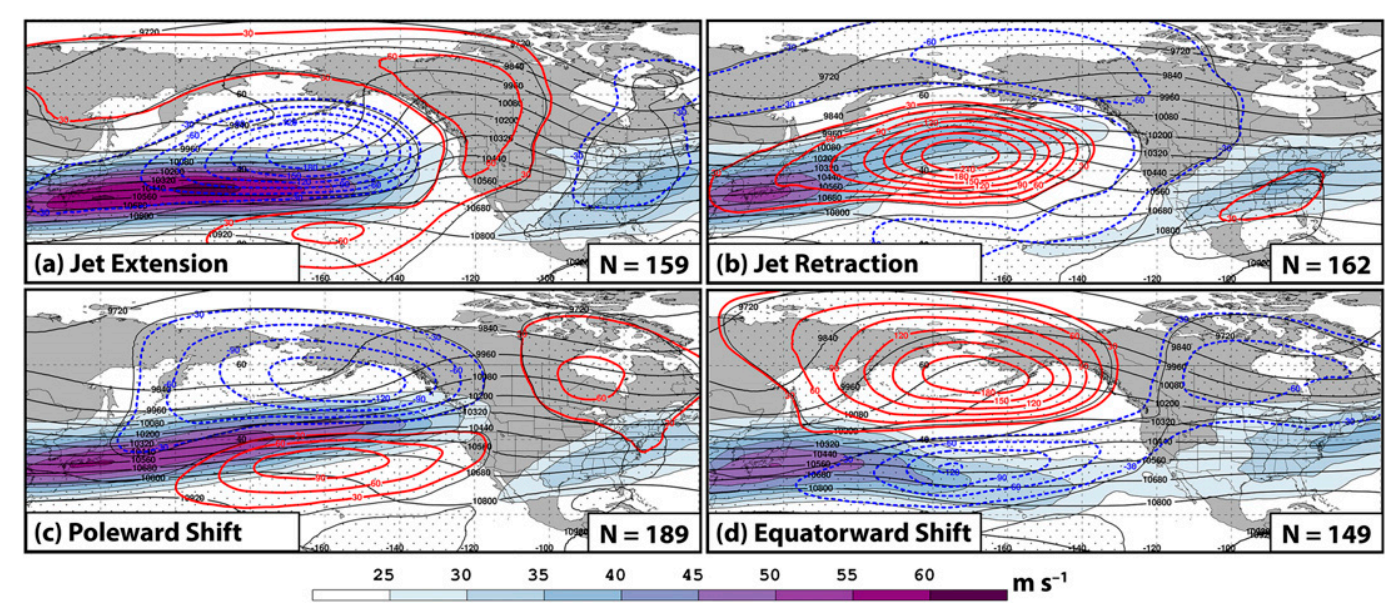

FIG. 6. Composite mean 250-hPa wind speed $\left(\mathrm{m} \mathrm{s}^{-1}\right)$ is shaded in the fill pattern, 250-hPa geopotential height is contoured in black every $120 \mathrm{~m}$, and 250-hPa geopotential height anomalies are contoured in solid red and dashed blue every $30 \mathrm{~m}$ for positive and negative values, respectively, 4 days following the initiation of (a) a jet extension, (b) a jet retraction, (c) a poleward shift, and (d) an equatorward shift regime. The numbers in the bottom right of each panel indicate the number of cases included in each composite and stippled areas represent locations where the $250-\mathrm{hPa}$ geopotential height anomalies are statistically distinct from climatology at the $99 \%$ confidence level using a two-sided Student's $t$ test. Figure and caption adapted from Winters et al. (2019). 

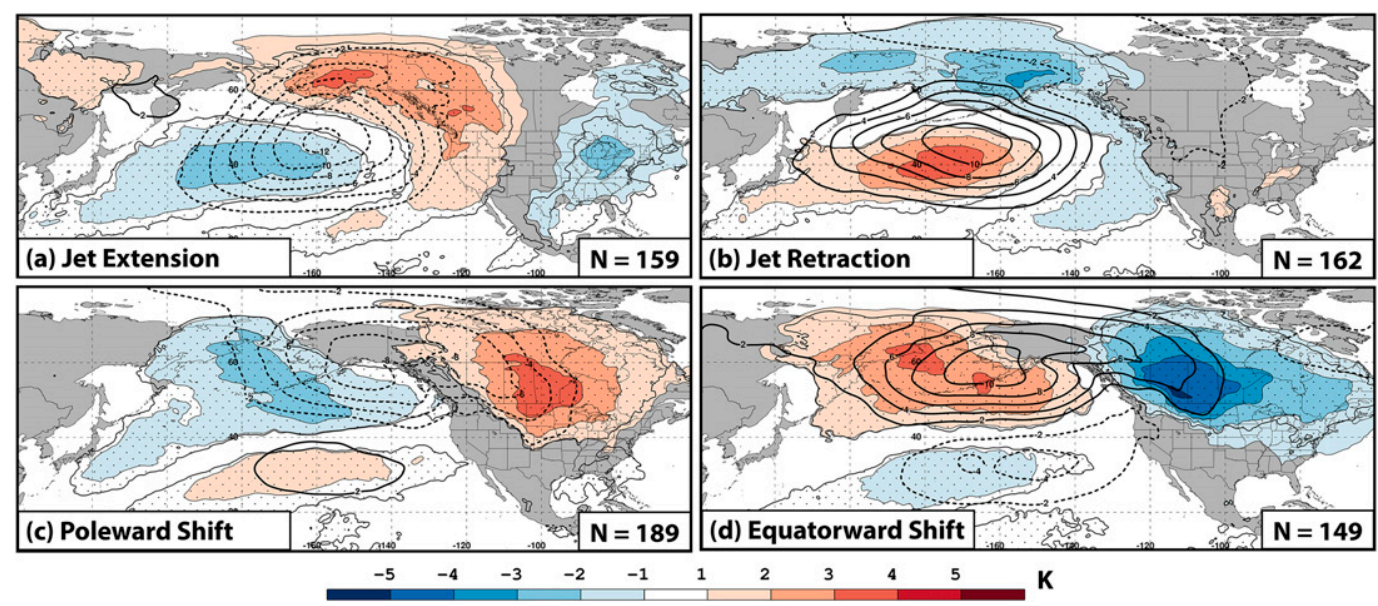

FIG. 7. Composite anomalies of mean sea level pressure are contoured in solid and dashed black every $2 \mathrm{hPa}$ for positive and negative values, respectively, and $850-\mathrm{hPa}$ temperature anomalies are shaded in the fill pattern every $1 \mathrm{~K} 4$ days following the initiation of (a) a jet extension, (b) a jet retraction, (c) a poleward shift, and (d) an equatorward shift regime. The numbers in the bottom right of each panel indicate the number of cases included in each composite and stippled areas represent locations where the 850-hPa temperature anomalies are statistically distinct from climatology at the $99 \%$ confidence level using a two-sided Student's $t$ test. Figure and caption adapted from Winters et al. (2019).

Considered together, the composite analyses suggest that certain parts of North America may be more susceptible than others to the development of an ETE based on the prevailing NPJ regime. To evaluate the validity of this suggestion, the prevailing NPJ regime prior to each continental U.S. ETE is determined by calculating the weighted PCs at 6-h intervals during the 3-7-day period prior to ETE initiation. The weighted PCs are then averaged to determine the mean position of the NPJ within the NPJ phase diagram 3-7 days prior ETE initiation. Last, every ETE is classified into an NPJ regime based on the mean position of the NPJ within the NPJ phase diagram prior to ETE initiation according to Fig. 5. This classification of ETEs based on the prevailing NPJ regime prior to ETE initiation is utilized in section 3 to determine the NPJ regimes and evolutions that are preferred prior to the development of ETEs.

Statistical significance with respect to the ETE classification scheme described in the previous paragraph is evaluated using a bootstrap resampling approach (e.g., Efron 1982; Wilks 2011, chapter 5). For each geographic cluster of ETEs, an equivalently sized, synthetic sample of analysis times is constructed by randomly selecting analysis times ${ }^{4}$ with replacement during the 36-yr period, 1979-2014, excluding the summer months. These analysis times are subsequently classified into

\footnotetext{
${ }^{4}$ To evaluate the significance of the ETE classification scheme during a particular season, the synthetic samples are constructed from analysis times drawn solely from that particular season.
}

NPJ regimes following the same scheme outlined in the previous paragraph for ETEs. For reference, a randomly selected analysis time has a nearly equivalent probability of being classified into each NPJ regime (not shown). We repeat this procedure 10000 times to construct a distribution for each NPJ regime that describes the number of analysis times characterized by that NPJ regime among all synthetic samples. Statistical significance is achieved if the number of ETEs associated with a particular NPJ regime ranks within the bottom or top 5th percentile of the distribution constructed from the 10000 synthetic samples for that NPJ regime.

\section{NPJ regimes and evolutions that precede cool season ETEs}

\section{a. Extreme warm events}

The frequency with which eastern U.S. extreme warm events initiate following each NPJ regime and during each meteorological season is shown in Fig. 8. Overall, eastern U.S. (Fig. 8a) extreme warm events most frequently initiate following jet retractions $(N=69)$ and poleward shifts $(N=66)$ during the cool season. Both jet retractions and poleward shifts are often associated with the presence of upper-tropospheric ridges (Figs. 6b,c) and above-normal lower-tropospheric temperatures (Figs. 7b,c) over parts of eastern North America. Consequently, jet retractions and poleward shifts exhibit large-scale flow patterns that are generally more conducive to the development of anomalous warmth over 
a) Eastern U.S. Extreme Warm Events
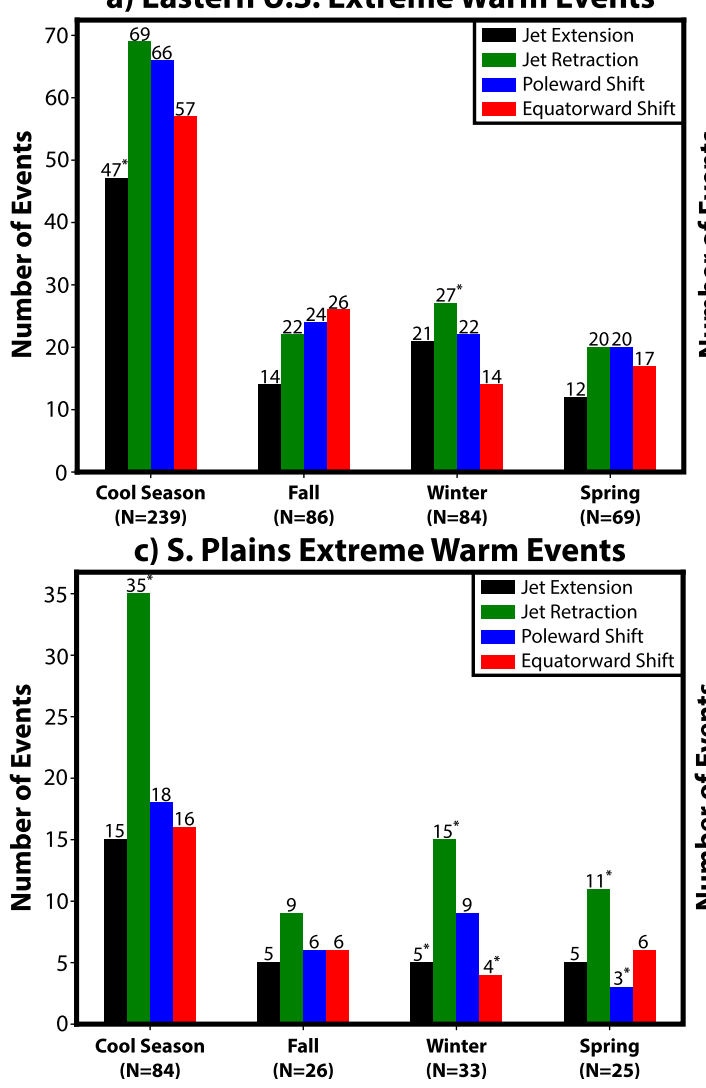

b) N. Plains Extreme Warm Events

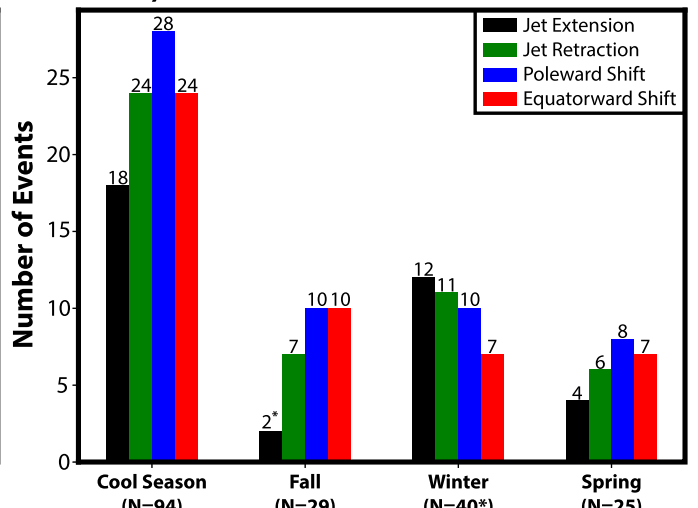

d) East Coast Extreme Warm Events

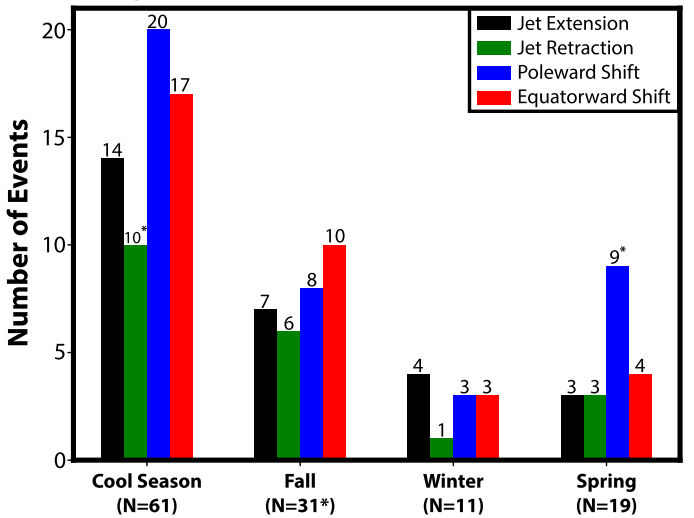

FIG. 8. (a) The number of eastern U.S. extreme warm events during the cool season (September-May), fall (September-November), winter (December-February), and spring (March-May) associated with each NPJ regime during the 3-7-day period prior to event initiation. The quantities listed above each bar indicate the number of events that are associated with a particular NPJ regime, and an asterisk indicates whether that quantity is statistically significant according to the bootstrap resampling test described in the text. (b)-(d) As in (a), but for Northern Plains, Southern Plains, and East Coast extreme warm events, respectively, during the cool season.

the eastern United States (Figs. 7b,c) than jet extensions and equatorward shifts (Figs. 7a,d). The preferred NPJ regime prior to eastern U.S. extreme warm event initiation during the cool season varies, however, based on the geographic location of event initiation. In particular, both Northern Plains (Fig. 8b) and East Coast (Fig. 8d) extreme warm events most frequently initiate following poleward shifts ( $N=28$ and $N=20$, respectively) during the cool season, while Southern Plains (Fig. 8c) events most frequently initiate following jet retractions $(N=35)$ by a large margin compared to the other NPJ regimes.

The most frequent NPJ regime prior to eastern U.S. extreme warm event initiation also varies seasonally, with the exception of Southern Plains events. Specifically, eastern U.S. (Fig. 8a) extreme warm events most frequently initiate following equatorward shifts $(N=26)$ during the fall, following jet retractions $(N=27)$ during the winter, and following both jet retractions $(N=20)$ and poleward shifts $(N=20)$ during the spring. While Northern Plains (Fig. 8b) and East Coast (Fig. 8d) extreme warm events also exhibit seasonal variability with respect to the preferred NPJ regime prior to event initiation, Southern Plains (Fig. 8c) events most frequently initiate following jet retractions during all seasons.

The frequency with which western U.S. extreme warm events initiate following each NPJ regime and during each meteorological season is shown in Fig. 9. Western U.S. (Fig. 9a) extreme warm events initiate more frequently following poleward shifts $(N=56)$, equatorward shifts $(N=54)$, and jet extensions $(N=53)$ compared to jet retractions $(N=41)$ during the cool season. The relatively low frequency of jet retractions prior to western U.S. extreme warm event initiation is consistent with the observation that jet retractions are the only NPJ regime associated with an anomalous upper-tropospheric trough (Fig. 6b) and below-normal lower-tropospheric temperatures (Fig. 7b) along the 
a) Western U.S. Extreme Warm Events

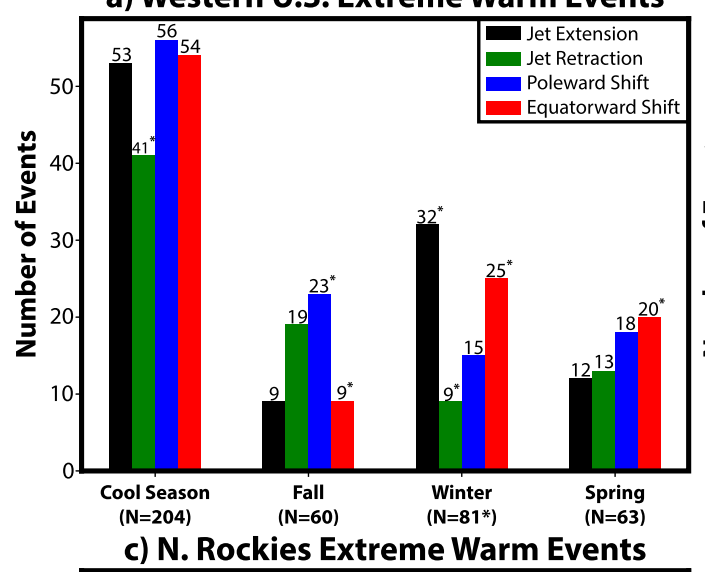

b) Pacific NW Extreme Warm Events

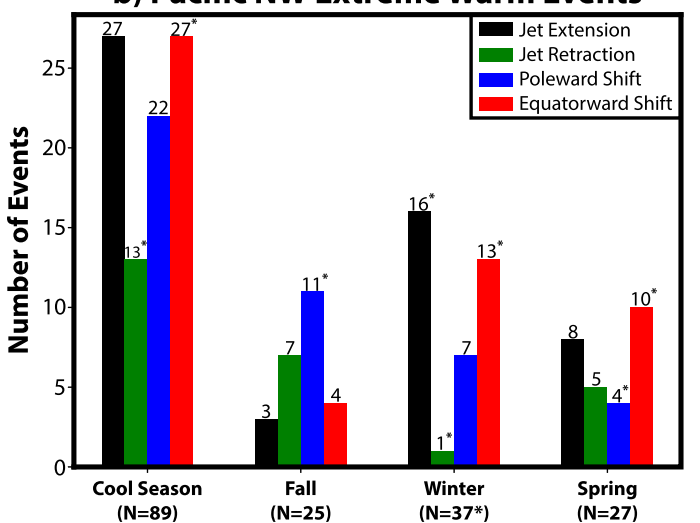

d) Southwest Extreme Warm Events

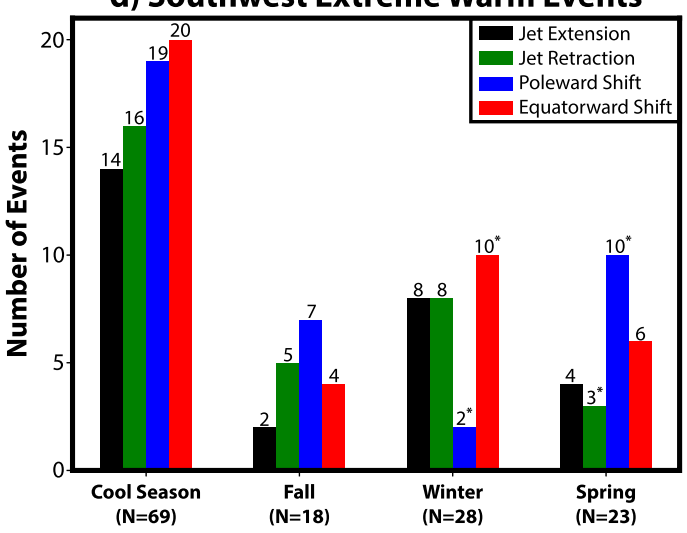

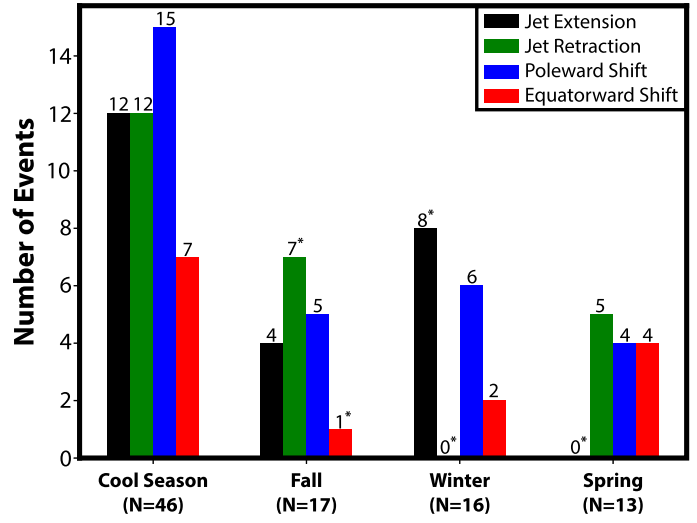

FIG. 9. As in Fig. 8, but for (a) western U.S., (b) Pacific Northwest, (c) Northern Rockies, and (d) Southwest extreme warm events during the cool season.

U.S. West Coast. Consequently, jet retractions are often associated with a large-scale flow pattern over the western United States that is generally less conducive to the development of anomalous warmth than the other NPJ regimes.

As observed for eastern U.S. extreme warm events, the most frequent NPJ regimes prior to western U.S. extreme warm event initiation during the cool season vary among the western U.S. geographic clusters. In particular, Pacific Northwest (Fig. 9b) extreme warm events most frequently initiate following jet extensions $(N=27)$ and equatorward shifts $(N=27)$ during the cool season, while Southwest (Fig. 9d) events most frequently initiate following equatorward shifts $(N=20)$ and poleward shifts $(N=19)$. Northern Rockies (Fig. 9c) extreme warm events initiate following poleward shifts $(N=15)$ with the highest frequency during the cool season and, unlike Pacific Northwest and Southwest events, initiate following equatorward shifts $(N=7)$ with the lowest frequency. The most frequent NPJ regimes prior to extreme warm event initiation also tend to vary based on the meteorological season for all western U.S. extreme warm events (Fig. 9a) and for those events within each western U.S. geographic cluster (Figs. 9b-d). For example, western U.S. extreme warm events (Fig. 9a) most frequently initiate following poleward shifts $(N=23)$ and jet retractions $(N=19)$ during the fall, following jet extensions $(N=32)$ and equatorward shifts $(N=25)$ during the winter, and following equatorward shifts $(N=20)$ and poleward shifts $(N=18)$ during the spring.

The construction of composite trajectories of the NPJ within the NPJ phase diagram provides an objective characterization of the evolution of the NPJ during the 10-day period prior to extreme warm event initiation and indicates how the NPJ evolution may differ based on the geographic location of an extreme warm event. Composite trajectories of the NPJ within the NPJ phase diagram are constructed by calculating the weighted PCs at 6-h intervals during the 10-day period prior to the initiation of each extreme warm event. The weighted PCs prior to each extreme warm event are then shifted so that the position of the NPJ always lies at the origin of the NPJ phase diagram 10 days prior to event initiation. This shift permits a comparison of the NPJ evolution prior to extreme warm event initiation between the 
Eastern Extreme Warm Events

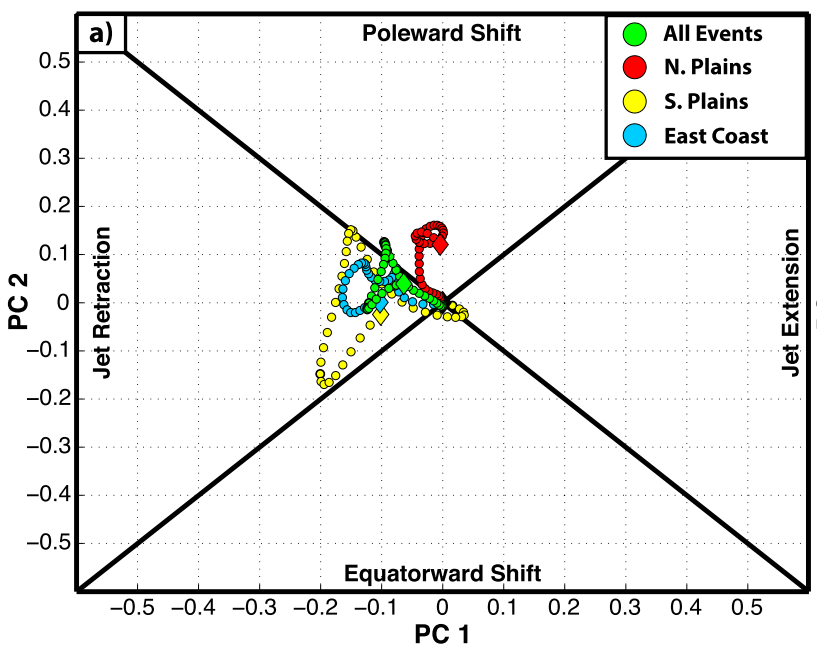

Western Extreme Warm Events

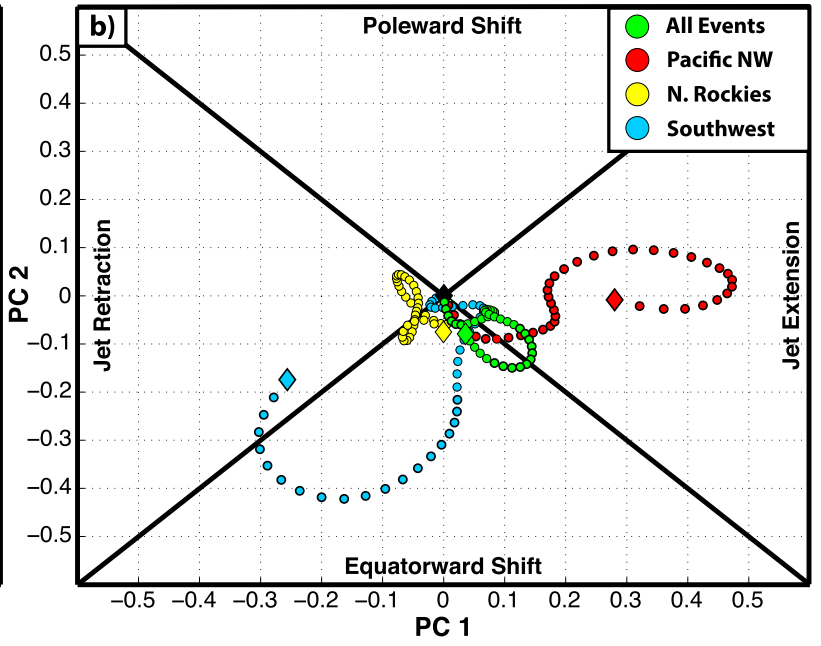

FIG. 10. (a) Composite trajectory showing the evolution of the NPJ at 6-h intervals during the 10-day period prior to event initiation for all eastern U.S. extreme warm events during the cool season and for extreme warm events within the three eastern U.S. geographic clusters. All trajectories are colored by geographic cluster according to the legend and are shifted such that they begin at the origin of the NPJ phase diagram 10 days prior to event initiation. The colored diamonds offset from the origin of the NPJ phase diagram correspond to the end point of a particular trajectory at the time of event initiation. Elements along the composite trajectory that feature a thick black outline represent 6-h intervals at which the value for PC 1 or PC 2 is statistically significant according to the bootstrap resampling test described in the text. (b) As in (a), but for all western U.S. extreme warm events and for the extreme warm events within the three western U.S. geographic clusters.

geographic clusters. Last, the weighted PCs that correspond to the same lead time prior to extreme warm event initiation are averaged across events within the same geographic cluster to construct a composite trajectory of the NPJ within the NPJ phase diagram. The statistical significance of PC 1 and PC 2 is evaluated at 6-h intervals along the composite trajectory using a bootstrap resampling approach that is analogous to the one outlined at the end of section $2 \mathrm{~b}$. In this test, statistical significance is achieved at a particular $6-\mathrm{h}$ interval along the composite trajectory if the value of PC 1 or PC 2 at that time ranks within the top or bottom 5th percentile among a distribution of 10000 randomly generated 10-day composite trajectories.

The composite trajectories of the NPJ within the NPJ phase diagram prior to all eastern U.S. extreme warm events and prior to events within each eastern U.S. geographic cluster are provided in Fig. 10a. Consistent with the observation that eastern U.S. extreme warm events most frequently initiate following jet retractions and poleward shifts during the cool season (Fig. 8a), the composite trajectory for all eastern U.S. extreme warm events indicates that the NPJ undergoes a retraction and poleward shift during the 10-day period prior to event initiation. A comparable trajectory is generally observed for extreme warm events within each eastern U.S. geographic cluster, with Northern Plains events characterized by an NPJ that undergoes a poleward shift, and Southern Plains and East Coast events characterized by an NPJ that undergoes a retraction.

The composite trajectory prior to all western U.S. (Fig. 10b) extreme warm events differs considerably from the trajectory prior to all eastern U.S. (Fig. 10a) events. In particular, the composite trajectory for all western U.S. extreme warm events indicates that the NPJ undergoes an extension and equatorward shift during the 10-day period prior to event initiation, rather than the retraction and poleward shift observed for all eastern U.S. events. The extension of the NPJ prior to all western U.S. extreme warm events is consistent with the observation that western U.S. events initiate following jet retractions with the lowest frequency during the cool season (Fig. 9a). Considered together, the trajectories shown in Figs. 10a,b demonstrate that knowledge of the evolution of the NPJ in the context of the NPJ phase diagram differentiates between NPJ evolutions that are generally more conducive to the development of extreme warm events in the eastern and western United States.

In contrast to the eastern U.S. geographic clusters, the trajectories associated with the western U.S. geographic clusters (Fig. 10b) differ notably from one another. Specifically, Pacific Northwest extreme warm events are characterized by an NPJ that undergoes an extension, Southwest events are characterized by an NPJ that undergoes an equatorward shift and retraction, and Northern Rockies events are characterized by an NPJ 

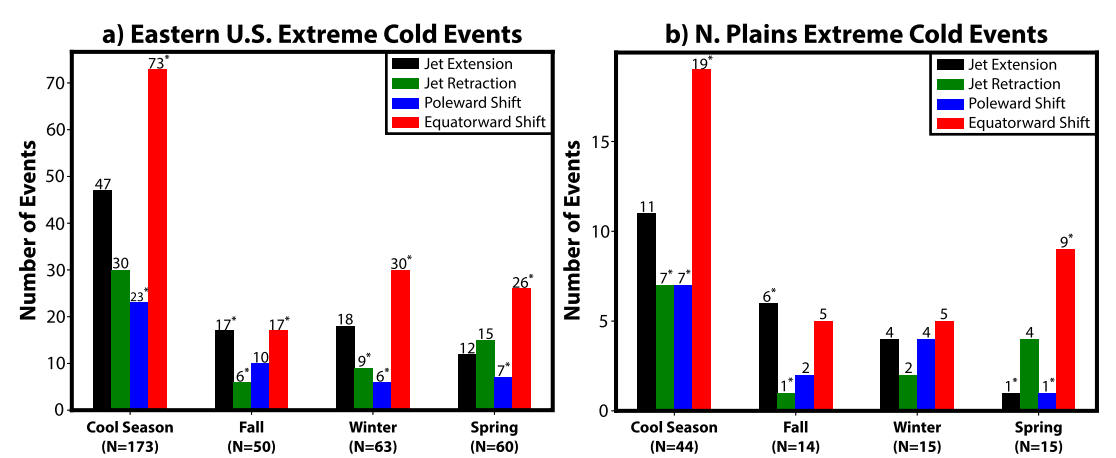

c) Northeast Extreme Cold Events
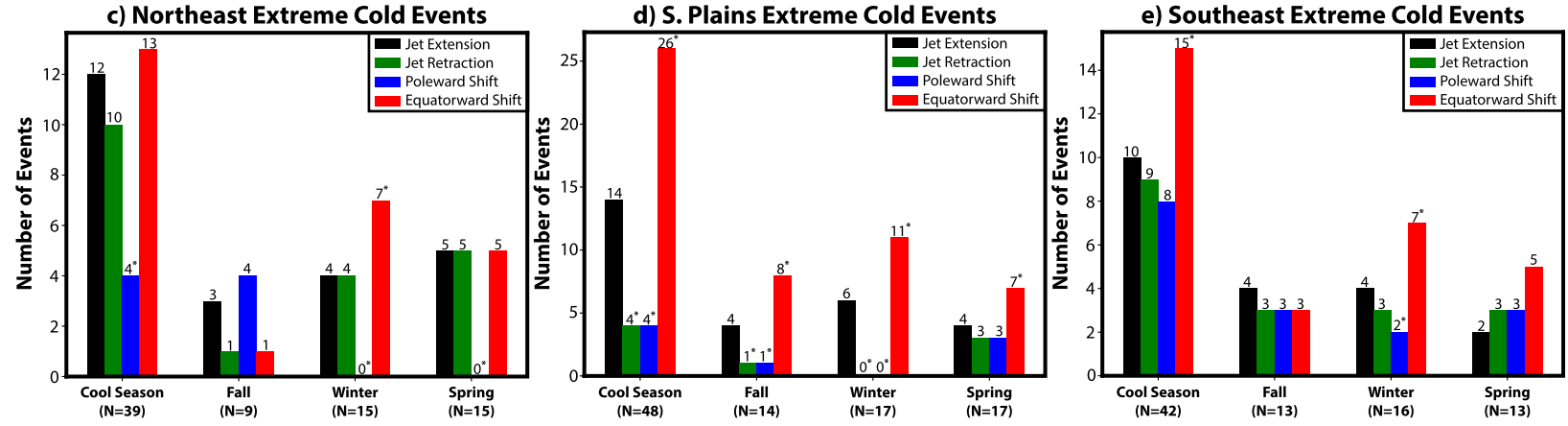

FIG. 11. As in Fig. 8, but for (a) eastern U.S., (b) Northern Plains, (c) Northeast, (d) Southern Plains, and (e) Southeast extreme cold events during the cool season.

that does not deviate far from the origin of the NPJ phase diagram during the 10-day period prior to event initiation. The trajectory for the Northern Rockies extreme warm events thus indicates that these events do not appear to have a preferred NPJ evolution prior to event initiation.

\section{b. Extreme cold events}

The frequency with which eastern U.S. extreme cold events initiate following each NPJ regime and during each meteorological season is shown in Fig. 11. Overall, eastern U.S. extreme cold events (Fig. 11a) most frequently initiate following equatorward shifts $(N=73)$ by a large margin compared to the other NPJ regimes during the cool season. Equatorward shifts are often associated with an anomalous upper-tropospheric trough (Fig. 6d) and below-normal lower-tropospheric temperatures (Fig. 7d) across northern North America to the east of the Rocky Mountains. Consequently, an equatorward shift is particularly conducive to the development of anomalous cold across the eastern United States in the event that the large-scale flow pattern can facilitate the equatorward transport of anomalously cold air from northern North America.

An examination of Figs. 11b-e further demonstrates that extreme cold events most frequently initiate following equatorward shifts during the cool season for each eastern U.S. geographic cluster. The similarity between geographic clusters with respect to the most frequent NPJ regime prior to extreme cold event initiation stands in contrast to the differences observed between geographic clusters with respect to the most frequent NPJ regime prior to eastern U.S. extreme warm event initiation (Figs. 8b-d). This contrast between the geographic clusters associated with eastern U.S. extreme cold events and warm events suggests that the upper-tropospheric flow patterns over the North Pacific prior to eastern U.S. extreme cold events are generally characterized by a lesser degree of variability than those prior to eastern U.S. extreme warm events.

The most frequent NPJ regime prior to eastern U.S. extreme cold events (Fig. 11a) varies as a function of meteorological season. In particular, eastern U.S. extreme cold events most frequently initiate following both jet extensions $(N=17)$ and equatorward shifts $(N=17)$ during the fall, and following only equatorward shifts during the winter $(N=30)$ and spring $(N=26)$. The Northern Plains (Fig. 11b), Northeast (Fig. 11c), and Southeast (Fig. 11e) clusters also exhibit seasonal variability with respect to the preferred NPJ regime prior to event initiation, while events within the Southern Plains (Fig. 11d) cluster most frequently initiate following equatorward shifts during all seasons.

The frequency with which western U.S. extreme cold events initiate following each NPJ regime and during each meteorological season is shown in Fig. 12. Western 
a) Western U.S. Extreme Cold Events

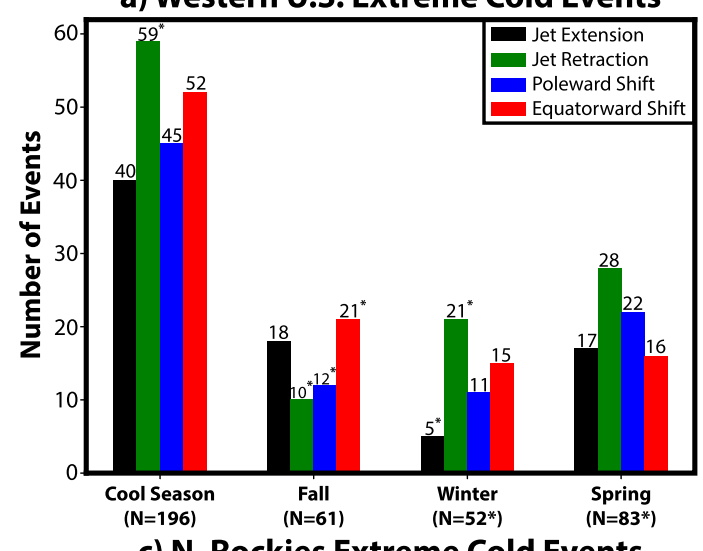

c) N. Rockies Extreme Cold Events

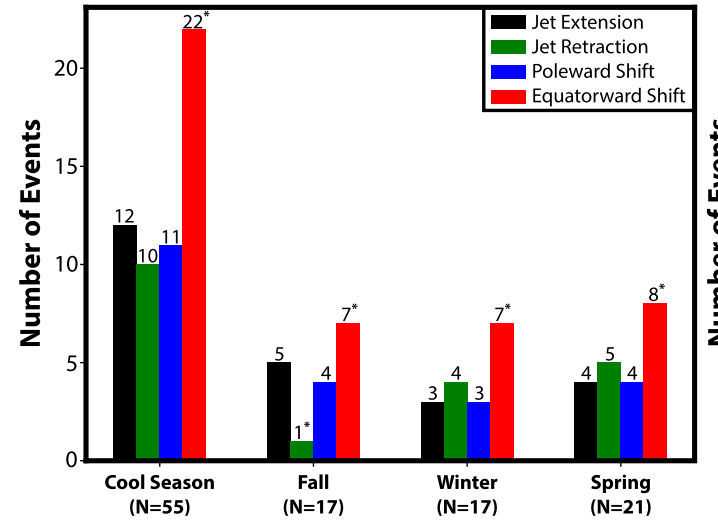

b) Pacific NW Extreme Cold Events

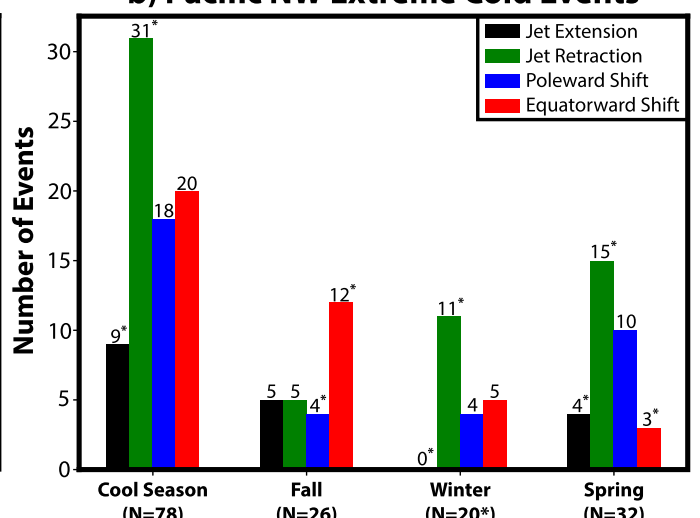

d) Southwest Extreme Cold Events

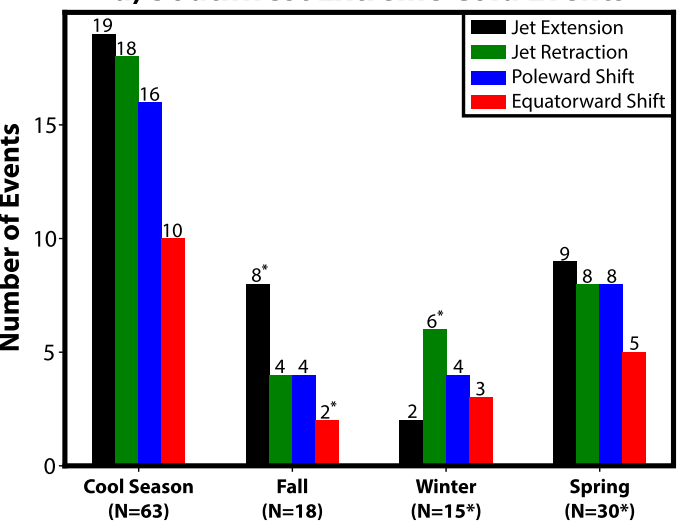

FIG. 12. As in Fig. 8, but for (a) western U.S., (b) Pacific Northwest, (c) Northern Rockies, and (d) Southwest extreme cold events during the cool season.

U.S. extreme cold events (Fig. 12a) most frequently initiate following jet retractions $(N=59)$ during the cool season, rather than with the lowest frequency $(N=41)$ as observed for western U.S. extreme warm events (Fig. 9a). Recall from section 3a that a jet retraction is the only NPJ regime associated with an anomalous upper-tropospheric trough (Fig. 6b) and below-normal lower-tropospheric temperatures (Fig. 7b) along the U.S. West Coast. Consequently, the large-scale flow pattern associated with a jet retraction is generally more conducive to the development of western U.S. extreme cold events than the other NPJ regimes. The most frequent NPJ regime prior to extreme cold event initiation during the cool season differs, however, between the western U.S. geographic clusters. In particular, Pacific Northwest (Fig. 12b) extreme cold events most frequently initiate following jet retractions $(N=31)$, Northern Rockies (Fig. 12c) events most frequently initiate following equatorward shifts $(N=22)$, and Southwest (Fig. 12d) events most frequently initiate following jet extensions $(N=19)$.

As for eastern U.S. extreme cold events (Fig. 11a), the most frequent NPJ regime prior to western U.S. extreme cold event initiation (Fig. 12a) varies seasonally. In particular, western U.S. extreme cold events most frequently initiate following equatorward shifts $(N=21)$ and jet extensions $(N=18)$ during the fall, and following jet retractions during the winter $(N=21)$ and spring $(N=28)$. While the most frequent NPJ regime prior to the initiation of Pacific Northwest (Fig. 12b) and Southwest (Fig. 12d) events also varies seasonally, Northern Rockies (Fig. 12c) events most frequently initiate following equatorward shifts during all seasons.

The composite trajectories of the NPJ within the NPJ phase diagram for all eastern (Fig. 13a) and all western (Fig. 13b) U.S. extreme cold events are comparable. Specifically, the composite trajectories for all eastern and all western U.S. extreme cold events both indicate that the NPJ undergoes an equatorward shift and slight extension during the 10-day period prior to event initiation. Therefore, in contrast to continental U.S. extreme warm events (Figs. 10a,b), knowledge of the evolution of the NPJ within the NPJ phase diagram alone does not differentiate between NPJ evolutions that are generally more conducive to extreme cold event initiation within the eastern and western United States. 
Eastern Extreme Cold Events

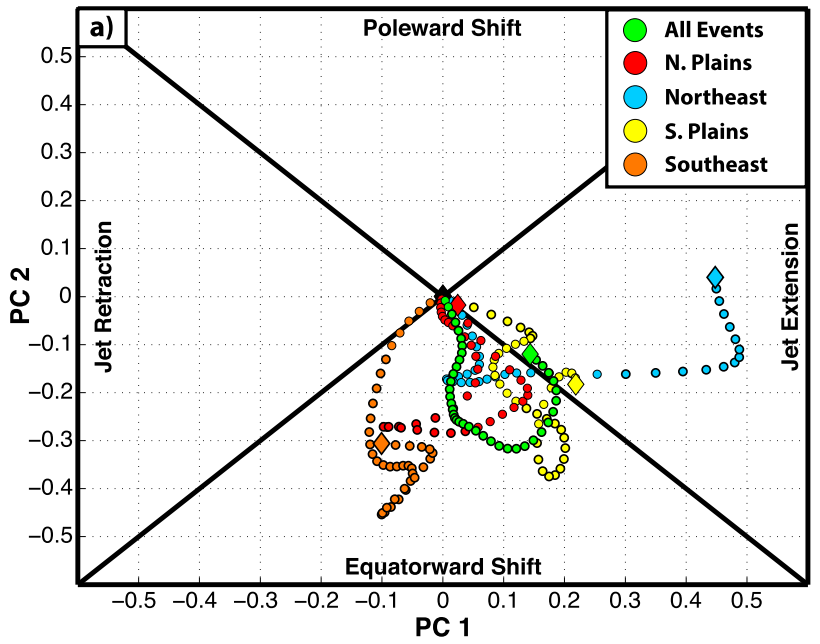

Western Extreme Cold Events

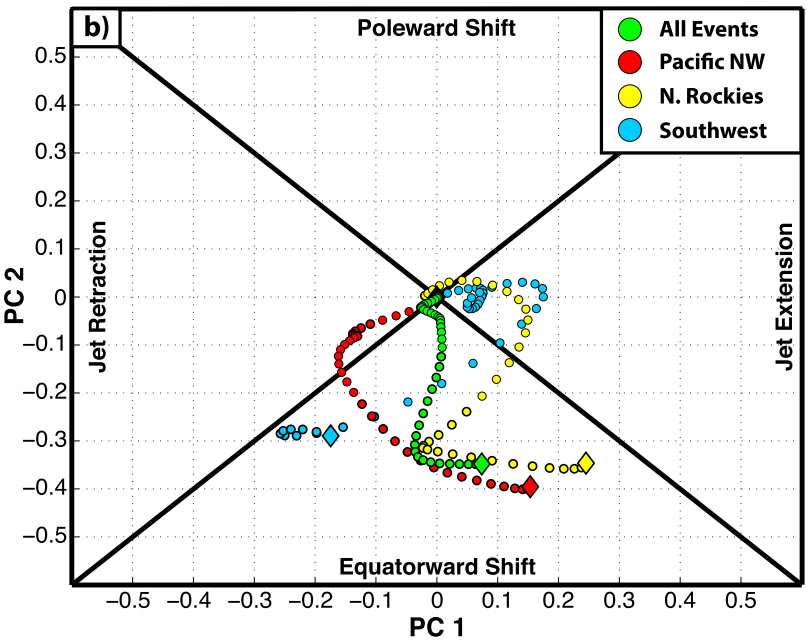

FIG. 13. As in Fig. 10, but for (a) all eastern U.S. and (b) all western U.S. extreme cold events during the cool season, and for those events within the four eastern U.S. and three western U.S. geographic clusters, respectively.

Subtle differences in the NPJ evolution prior to extreme cold event initiation are observed between the geographic clusters. Similar to the trajectory for all eastern U.S. extreme cold events, the composite trajectories prior to the initiation of Northern Plains, Southern Plains, and Southeast events indicate that the NPJ primarily undergoes an equatorward shift during the 10-day period prior to event initiation (Fig. 13a). The composite trajectory prior to the initiation of Northeast extreme cold events differs from the other eastern U.S. clusters, however, with the NPJ undergoing an extension rather than an equatorward shift during the 10-day period prior to event initiation. The Pacific Northwest and Northern Rockies trajectories are comparable to the trajectory for all western U.S. extreme cold events in that they both show the NPJ undergoing an equatorward shift and slight extension by the time of event initiation (Fig. 13b). The Southwest trajectory also indicates that the NPJ undergoes an equatorward shift but, unlike the Pacific Northwest and Northern Rockies trajectories, the NPJ evolves toward a slight retraction, rather than a slight extension, by the time of event initiation.

\section{Composite evolution of Southern Plains extreme warm events preceded by a jet retraction}

The discussion in section 3 demonstrates that the most frequent NPJ regime and evolution prior to continental U.S. ETEs during the cool season can vary considerably based on the type of ETE and the geographic location of ETE initiation. Given these results, the NPJ phase diagram can be utilized to isolate ETEs within a particular geographic location that initiate following the same NPJ regime during the cool season. A composite analysis performed on the isolated ETEs subsequently reveals the synoptic-dynamic mechanisms that allow the flow to evolve from an antecedent NPJ regime to ETE initiation within a particular geographic region. The forthcoming discussion provides an illustrative example that exposes the utility of such an analysis by investigating the synoptic-scale flow evolution most conducive to Southern Plains extreme warm events. The Southern Plains cluster is selected for analysis given that it is the only geographic cluster in which the most frequent NPJ regime prior to extreme warm event initiation does not vary seasonally (Fig. 8c). Furthermore, extreme warm events during the cool season are selected due to the limited scrutiny warm events have received in the refereed literature compared to cold events.

As discussed in section 3a, Southern Plains extreme warm events (Fig. 8c) most frequently initiate following jet retractions $(N=35)$ by a large margin compared to the other NPJ regimes during the cool season. Consequently, a composite analysis of the synoptic-scale flow evolution most conducive to Southern Plains extreme warm event initiation during the cool season is performed by isolating only those Southern Plains extreme warm events that are characterized by a jet retraction prior to event initiation. The latitude and longitude of the individual Southern Plains event centroids (Fig. 2a) are then averaged to determine the position of a composite centroid. The composite analyses are constructed, first, by shifting the CFSR data for each event so that each individual event centroid matches the position of the composite centroid and, second, by averaging the shifted CFSR data at each grid point within 

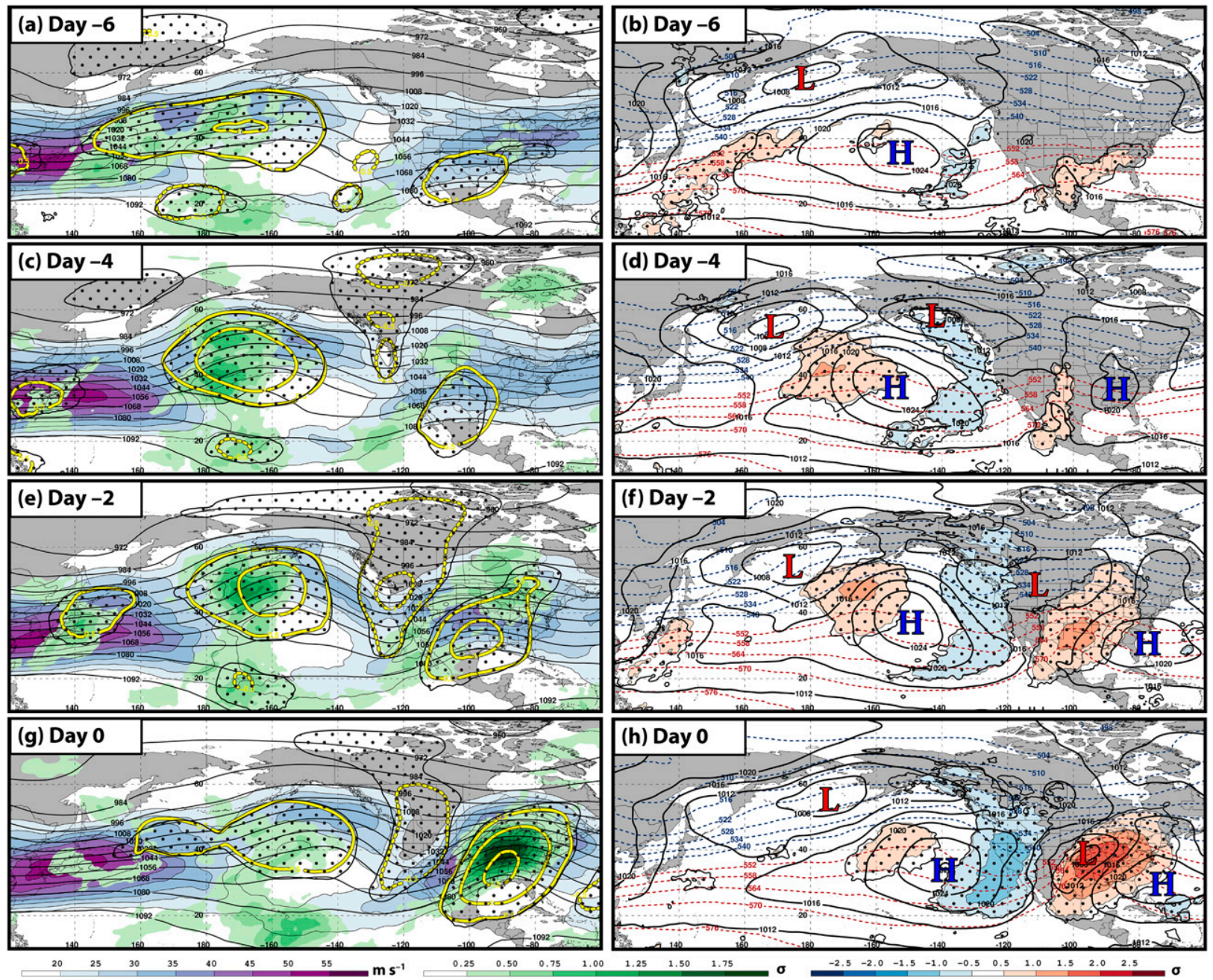

FIG. 14. Composite synoptic-scale flow evolution prior to the initiation of a Southern Plains extreme warm event following a jet retraction during the cool season. (left) The 250-hPa wind speed is shaded $\left(\mathrm{m} \mathrm{s}^{-1}\right)$ according to the legend, 250 -hPa geopotential height is contoured in black every $12 \mathrm{dam}$, standardized 250-hPa geopotential height anomalies are contoured in solid and dashed yellow every $0.5 \sigma$ for positive and negative values, respectively, and positive standardized precipitable water anomalies are shaded in green according to the legend for (a) 6, (c) 4, (e) 2, and (g) 0 days prior to extreme warm event initiation. Stippled areas represent locations where the 250-hPa geopotential height anomalies are statistically distinct from climatology at the $99 \%$ confidence level. (right) Standardized 850-hPa temperature anomalies are shaded every $0.5 \sigma$ according to the legend, mean sea level pressure is contoured in black every $4 \mathrm{hPa}$, and $1000-500-\mathrm{hPa}$ thickness is contoured in dashed red and blue for values greater than 540 dam and less than or equal to 540 dam, respectively, for (b) 6, (d) 4, (f) 2 , and (h) 0 days prior to extreme warm event initiation. The red "L"s and blue "H"s identify the locations of surface cyclones and anticyclones. Stippled areas represent locations where the $850-\mathrm{hPa}$ temperature anomalies are statistically distinct from climatology at the $99 \%$ confidence level.

the horizontal domain shown in Fig. 14 across all cases. A two-sided Student's $t$ test is performed on composite $250-\mathrm{hPa}$ geopotential height anomalies and $850-\mathrm{hPa}$ temperature anomalies to identify regions that are statistically distinct from climatology at the $99 \%$ confidence level.

The composite evolution of the synoptic-scale flow pattern during the 6-day period prior to event initiation is provided in Fig. 14. An anomalous upper-tropospheric ridge is located over the central North Pacific 6 days prior to event initiation, resulting in a retracted NPJ over the western North Pacific and a split NPJ to the east of the date line (Fig. 14a). Farther downstream, an anomalous upper-tropospheric ridge is collocated with an inverted trough and above-normal $850-\mathrm{hPa}$ temperatures over the Southern Plains and northern Mexico (Fig. 14b), suggesting that the synoptic-scale environment may be preconditioned for the development of extreme warmth in those locations. To this point, the composite flow pattern features westerly midlevel flow 
over the Southern Plains and northern Mexico at this time (not shown), which supports the development of the inverted trough and above-normal 850-hPa temperatures observed over these locations as air subsides and warms adiabatically in the lee of higher terrain.

Four days prior to event initiation, the anomalous North Pacific ridge amplifies compared to the prior time in conjunction with surface cyclogenesis beneath the left-exit region of the retracted NPJ (Figs. 14c,d). Specifically, the surface cyclone facilitates lower-tropospheric warm-air advection over the central North Pacific that contributes to both upper-tropospheric geopotential height rises and forcing for quasigeostrophic ascent (not shown). The occurrence of implied ascent in the presence of positive precipitable water anomalies over the central North Pacific suggests that latent heating is likely associated with any regions of ascent and, consequently, that diabatic processes also contribute to the observed ridge amplification. The role of diabatic processes during ridge amplification has been noted by a number of studies (e.g., Massacand et al. 2001; Riemer et al. 2008; Torn 2010; Grams et al. 2011; Madonna et al. 2014; Pfahl et al. 2015; Torn and Hakim 2015; Grams and Archambault 2016; Bosart et al. 2017).

Central North Pacific ridge amplification subsequently leads to an amplification of the downstream upper-tropospheric flow pattern 2 days prior to event initiation (Fig. 14e), including the development of a positively tilted upper-tropospheric trough along the west coast of North America and additional ridge amplification over the Southern Plains. The amplified upper-tropospheric flow pattern supports lee cyclogenesis downstream of the northern U.S. Rocky Mountains and surface anticyclogenesis over the southeast United States (Fig. 14f). The configuration of the pressure gradient between the lee cyclone and surface anticyclone induces southwesterly geostrophic flow over central North America and the concomitant advection of anomalous warmth from both northern Mexico and the western Gulf of Mexico toward the Southern Plains.

At the time of event initiation, the lee cyclone intensifies compared to the prior time beneath the entrance region of a $250-\mathrm{hPa}$ jet streak and in conjunction with further amplification of the upper-tropospheric flow pattern (Figs. 14g,h). The more intense lee cyclone subsequently facilitates stronger southwesterly geostrophic flow over the Southern Plains than at the prior time, which ensures that the advection of anomalous warmth toward the Southern Plains continues unabated until the time of event initiation. The composite evolution also features strong poleward moisture advection from the western Gulf of Mexico in the lower troposphere during the 2-day period prior to event initiation (not shown), resulting in the large positive precipitable water anomalies observed over the middle Mississippi River valley at the time of event initiation (Fig. 14g). Given the strong dynamical forcing for ascent provided by the amplified upper-tropospheric flow pattern and the presence of the lee cyclone, the evolution of a Southern Plains extreme warm event strongly resembles synoptic-scale flow evolutions that are conducive to eastern U.S. extreme precipitation events during the cool season (e.g., Moore et al. 2015; Moore 2017). Consequently, it is hypothesized that extreme precipitation events may often accompany Southern Plains extreme warm events.

\section{Discussion}

The utility of the NPJ phase diagram is that it provides a common framework for characterizing the antecedent large-scale flow patterns associated with continental U.S. ETEs during the cool season. Overall, eastern U.S. extreme warm events are most frequent following jet retractions and poleward shifts and are characterized by an NPJ that evolves toward those same two NPJ regimes within the NPJ phase diagram during the 10-day period prior to event initiation. Western U.S. extreme warm events are the least frequent following jet retractions and are characterized by an NPJ that evolves toward a jet extension and equatorward shift during the 10-day period prior to event initiation. Eastern U.S. extreme cold events are most frequent following equatorward shifts compared to the other NPJ regimes by a large margin, while western U.S. extreme cold events are most frequent following jet retractions. Furthermore, both eastern and western U.S. extreme cold events are characterized by an NPJ that evolves toward an equatorward shift and a slight jet extension during the 10-day period prior to event initiation. The NPJ regimes that most frequently precede extreme warm and cold event initiation within parts of the continental United States during the cool season are those that feature anomalously warm and cold lower-tropospheric temperatures within the same parts of the continental United States, respectively, during a typical period characterized by those NPJ regimes (Fig. 7). Consequently, the results from the present study suggest that knowledge of the prevailing NPJ regime and the subsequent NPJ evolution provides an indication as to whether the large-scale flow pattern is more conducive to the development of eastern and western U.S. ETEs compared to climatology.

While the NPJ regimes and evolutions described above are those that most frequently precede all eastern and all western U.S. ETEs during the cool season, the most frequent NPJ regime prior to ETE initiation varies 
considerably within the eastern and western U.S. domains based on the specific geographic location of ETE initiation and the meteorological season. The considerable geographic and seasonal variability that characterizes the most frequent NPJ regime prior to ETE initiation is indicative of the variety of large-scale flow evolutions that are conducive to ETE initiation within a specific geographic location. The NPJ phase diagram and the results from the present study provide a foundation for detailed synoptic-dynamic investigations into the variety of large-scale flow evolutions that facilitate ETE initiation within specific geographic locations.

As an illustrative example, the NPJ phase diagram was utilized to examine the large-scale flow evolution that is most conducive to the initiation of Southern Plains extreme warm events during the cool season, given that extreme warm events in that location most frequently initiate following jet retractions during all seasons. The composite analysis suggests that Southern Plains extreme warm event initiation is dynamically driven within an environment that is preconditioned for above-normal lower-tropospheric temperatures. Specifically, a retracted NPJ supports an amplification of the upper-tropospheric flow pattern over North America, which subsequently induces the transport of an anomalously warm lower-tropospheric air mass toward the Southern Plains prior to event initiation.

The analysis performed for Southern Plains extreme warm events can be extended to investigate the largescale flow evolutions conducive to ETE initiation in other geographic clusters. For instance, in geographic clusters where multiple NPJ regimes are frequently observed prior to ETE initiation, such as for Pacific Northwest extreme cold events, the NPJ phase diagram can be utilized to categorize ETEs based on the antecedent NPJ regime. Composite analyses can then be performed on events that are preceded by the same NPJ regime in order to examine the differences between a set of large-scale flow evolutions that are mutually conducive to ETE initiation, and to identify the characteristic origins of anomalously warm and cold air masses during the selected events. While not shown, it is hypothesized that subtle differences in the location and character of upper-tropospheric flow amplification over the North Pacific may explain the differences between geographic clusters regarding the preferred NPJ regime and evolution prior to ETE initiation.

The capability of the NPJ phase diagram to identify NPJ regimes and evolutions that are conducive to the development of ETEs suggests that the NPJ phase diagram may have additional utility during the preparation of operational medium-range (6-10 day) and week two (8-14 day) temperature forecasts over the continental
United States. In particular, the NPJ phase diagram can be employed operationally to determine both the prevailing NPJ regime and the forecast evolution of the NPJ in real time. Knowledge of the prevailing NPJ regime and evolution can then be paired with the results from the present study to identify geographic locations that may be susceptible to the development of extreme lower-tropospheric temperatures during the mediumrange and week two periods. Furthermore, Winters et al. (2019) indicate that certain NPJ regimes are generally characterized by enhanced or reduced medium-range forecast skill compared to climatology. Consequently, studies that examine the medium-range forecast skill of large-scale environments prior to ETEs with respect to the NPJ phase diagram may reveal whether certain large-scale flow evolutions prior to ETEs exhibit enhanced or reduced forecast skill.

Last, the NPJ phase diagram can be utilized to examine the variability in NPJ regimes that precede other types of North American EWEs during the cool season. As demonstrated for ETEs, the application of the NPJ phase diagram can provide additional understanding of the variety of large-scale environments that are conducive to extreme precipitation events (e.g., Moore et al. 2015; Moore 2017), landfalling atmospheric river events (e.g., Zhu and Newell 1998; Ralph et al. 2004; Neiman et al. 2008; Cordeira et al. 2013; Mundhenk et al. 2016; Gershunov et al. 2017), severe weather outbreaks (e.g., Cook and Schaefer 2008; Allen et al. 2015; Tippett et al. 2015; Gensini and Marinaro 2016; Cook et al. 2017), and rapidly deepening midlatitude cyclones (e.g., Sanders and Gyakum 1980; Bosart et al. 1996; Isard et al. 2000; Grise et al. 2013; Bentley 2018). Results that emerge from these applications of the NPJ phase diagram may translate into improved operational forecasts of EWEs.

Acknowledgments. The authors thank Mike Bodner, Daniel Halperin, Arlene Laing, Bill Lamberson, Sara Ganetis, and Josh Kastman for their constructive discussions concerning the NPJ phase diagram. The authors also thank the National Oceanic and Atmospheric Administration for its support of this work via Grant NA15NWS4680006 and the National Science Foundation for its support of this work via Grants AGS-1355960 and AGS-1656406.

\section{REFERENCES}

Allen, J. T., M. K. Tippett, and A. H. Sobel, 2015: Influence of the El Niño/Southern Oscillation on tornado and hail frequency in the United States. Nat. Geosci., 8, 278-283, https://doi.org/ 10.1038/ngeo2385.

Athanasiadis, P. J., J. M. Wallace, and J. J. Wettstein, 2010: Patterns of wintertime jet stream variability and their relation to 
the storm tracks. J. Atmos. Sci., 67, 1361-1381, https://doi.org/ 10.1175/2009JAS3270.1.

Barnston, A. G., and R. E. Livezey, 1987: Classification, seasonality, and persistence of low-frequency atmospheric circulation patterns. Mon. Wea. Rev., 115, 1083-1126, https://doi.org/ 10.1175/1520-0493(1987)115<1083:CSAPOL > 2.0.CO;2.

Bell, G. D., and L. F. Bosart, 1988: Appalachian cold-air damming. Mon. Wea. Rev., 116, 137-161, https://doi.org/10.1175/ 1520-0493(1988)116<0137:ACAD>2.0.CO;2.

Bentley, A. M., 2018: Extratropical cyclones leading to extreme weather events over central and eastern North America. Ph.D. dissertation, University at Albany, State University of New York, $158 \mathrm{pp}$.

Bosart, L. F., G. J. Hakim, K. R. Tyle, M. A. Bedrick, W. E. Bracken, M. J. Dickinson, and D. M. Schultz, 1996: Largescale antecedent conditions associated with the 12-14 March 1993 cyclone ("Superstorm '93") over eastern North America. Mon. Wea. Rev., 124, 1865-1891, https://doi.org/10.1175/ 1520-0493(1996)124<1865:LSACAW >2.0.CO;2.

— B. J. Moore, J. M. Cordeira, and H. M. Archambault, 2017: Interactions of North Pacific tropical, midlatitude, and polar disturbances resulting in linked extreme weather events over North America in October 2007. Mon. Wea. Rev., 145, 12451273, https://doi.org/10.1175/MWR-D-16-0230.1.

Brewer, M. C., C. F. Mass, and B. E. Potter, 2012: The West Coast thermal trough: Climatology and synoptic evolution. Mon. Wea. Rev., 140, 3820-3843, https://doi.org/10.1175/MWR-D-12-00078.1. - — _ and — , 2013: The West Coast thermal trough: Mesoscale evolution and sensitivity to terrain and surface fluxes. Mon. Wea. Rev., 141, 2869-2896, https://doi.org/10.1175/ MWR-D-12-00305.1.

Carrera, M. L., R. W. Higgins, and V. E. Kousky, 2004: Downstream weather impacts associated with atmospheric blocking over the northeast Pacific. J. Climate, 17, 4823-4839, https:// doi.org/10.1175/JCLI-3237.1.

Cellitti, M. P., J. E. Walsh, R. M. Rauber, and D. H. Portis, 2006: Extreme cold air outbreaks over the United States, the polar vortex, and the large-scale circulation. J. Geophys. Res., 111, D02114, https://doi.org/10.1029/2005JD006273.

Colle, B. A., and C. F. Mass, 1995: The structure and evolution of cold surges east of the Rocky Mountains. Mon. Wea. Rev., 123, 2577-2610, https://doi.org/10.1175/1520-0493(1995)123<2577: TSAEOC $>2.0 . C O ; 2$.

Colucci, S. J., and J. C. Davenport, 1987: Rapid surface anticyclogenesis: Synoptic climatology and attendant large-scale circulation changes. Mon. Wea. Rev., 115, 822-836, https://doi.org/ 10.1175/1520-0493(1987)115<0822:RSASCA > 2.0.CO;2.

Cook, A. R., and J. T. Schaefer, 2008: The relation of El NiñoSouthern Oscillation (ENSO) to winter tornado outbreaks. Mon. Wea. Rev., 136, 3121-3137, https://doi.org/10.1175/ 2007MWR2171.1.

—, L. M. Leslie, D. B. Parsons, and J. T. Schaefer, 2017: The impact of El Niño-Southern Oscillation (ENSO) on winter and early spring U.S. tornado outbreaks. J. Appl. Meteor. Climatol., 56, 2455-2478, https://doi.org/10.1175/JAMC-D-16-0249.1.

Cordeira, J. M., and L. F. Bosart, 2010: The antecedent large-scale conditions of the "Perfect Storms" of late October and early November 1991. Mon. Wea. Rev., 138, 2546-2569, https:// doi.org/10.1175/2010MWR3280.1.

, F. M. Ralph, and B. J. Moore, 2013: The development and evolution of two atmospheric rivers in proximity to western North Pacific tropical cyclones in October 2010. Mon. Wea. Rev., 141, 4234-4255, https://doi.org/10.1175/MWR-D-13-00019.1.
Dallavalle, J. P., and L. F. Bosart, 1975: A synoptic investigation of anticyclogenesis accompanying North American polar air outbreaks. Mon. Wea. Rev., 103, 941-957, https://doi.org/ 10.1175/1520-0493(1975)103<0941:ASIOAA > 2.0.CO;2.

Dole, R., and Coauthors, 2014: The making of an extreme event: Putting the pieces together. Bull. Amer. Meteor. Soc., 95, 427440, https://doi.org/10.1175/BAMS-D-12-00069.1.

Downton, M. W., and K. A. Miller, 1993: The freeze risk to Florida citrus. Part II: Temperature variability and circulation patterns. J. Climate, 6, 364-372, https://doi.org/10.1175/ 1520-0442(1993)006<0364:TFRTFC $>2.0 . \mathrm{CO} ; 2$.

Efron, B., 1982: The Jackknife, the Bootstrap, and Other Resampling Plans. Society for Industrial and Applied Mathematics, $92 \mathrm{pp}$.

Gensini, V. A., and A. Marinaro, 2016: Tornado frequency in the United States related to global relative angular momentum. Mon. Wea. Rev., 144, 801-810, https://doi.org/10.1175/ MWR-D-15-0289.1.

Gershunov, A., T. Shulgina, F. M. Ralph, D. A. Lavers, and J. J. Rutz, 2017: Assessing the climate-scale variability of atmospheric rivers affecting western North America. Geophys. Res. Lett., 44, 7900-7908, https://doi.org/10.1002/2017GL074175.

Grams, C. M., and H. M. Archambault, 2016: The key role of diabatic outflow in amplifying the midlatitude flow: A representative case study of weather systems surrounding western North Pacific extratropical transition. Mon. Wea. Rev., 144, 3847-3869, https://doi.org/10.1175/MWR-D-15-0419.1.

_ - and Coauthors, 2011: The key role of diabatic processes in modifying the upper-tropospheric wave guide: A North Atlantic case-study. Quart. J. Roy. Meteor. Soc., 137, 21742193, https://doi.org/10.1002/qj.891.

Griffin, K. S., and J. E. Martin, 2017: Synoptic features associated with temporally coherent modes of variability of the North Pacific jet stream. J. Climate, 30,39-54, https://doi.org/10.1175/ JCLI-D-15-0833.1.

Grise, K. M., S.-W. Son, and J. R. Gyakum, 2013: Intraseasonal and interannual variability in North American storm tracks and its relationship to equatorial Pacific variability. Mon. Wea. Rev., 141, 3610-3625, https://doi.org/10.1175/MWR-D-12-00322.1.

Grotjahn, R., and R. Zhang, 2017: Synoptic analysis of cold air outbreaks over the California Central Valley. J. Climate, 30, 9417-9433, https://doi.org/10.1175/JCLI-D-17-0167.1.

_ - and Coauthors, 2016: North American extreme temperature events and related large scale meteorological patterns: A review of statistical methods, dynamics, modeling, and trends. Climate Dyn., 46, 1151-1184, https://doi.org/10.1007/ s00382-015-2638-6.

Gu, L., P. J. Hanson, W. Mac Post, D. P. Kaiser, B. Yang, R. Nemani, S. G. Pallardy, and T. Meyers, 2008: The 2007 eastern US spring freeze: Increased cold damage in a warming world? BioScience, 58, 253-262, https://doi.org/10.1641/ B580311.

Guirguis, K., A. Gershunov, R. Schwartz, and S. Bennett, 2011: Recent warm and cold daily winter temperature extremes in the Northern Hemisphere. Geophys. Res. Lett., 38, L17701, https://doi.org/10.1029/2011GL048762.

Hartjenstein, G., and R. Bleck, 1991: Factors affecting cold-air outbreaks east of the Rocky Mountains. Mon. Wea. Rev., 119 2280-2292, https://doi.org/10.1175/1520-0493(1991)119<2280: FACAOE $>2.0 . \mathrm{CO} ; 2$.

Hartmann, D. L., 2015: Pacific sea surface temperature and the winter of 2014. Geophys. Res. Lett., 42, 1894-1902, https:// doi.org/10.1002/2015GL063083. 
Higgins, R. W., A. Leetmaa, and V. E. Kousky, 2002: Relationships between climate variability and winter temperature extremes in the United States. J. Climate, 15, 1555-1572, https://doi.org/ 10.1175/1520-0442(2002)015<1555:RBCVAW > 2.0.CO;2.

Hoerling, M., and Coauthors, 2013: Anatomy of an extreme event. J. Climate, 26, 2811-2832, https://doi.org/10.1175/ JCLI-D-12-00270.1.

Isard, S. A., J. R. Angel, and G. T. VanDyke, 2000: Zones of origin for Great Lakes cyclones in North America, 18991996. Mon. Wea. Rev., 128, 474-485, https://doi.org/10.1175/ 1520-0493(2000)128<0474:ZOOFGL > 2.0.CO;2.

Jaffe, S. C., J. E. Martin, D. J. Vimont, and D. J. Lorenz, 2011: A synoptic climatology of episodic, subseasonal retractions of the Pacific jet. J. Climate, 24, 2846-2860, https://doi.org/ 10.1175/2010JCLI3995.1.

Kenyon, J., and G. C. Hegerl, 2008: Influence of modes of climate variability on global temperature extremes. J. Climate, 21, 3872-3889, https://doi.org/10.1175/2008JCLI2125.1.

Konrad, C. E., II, 1996: Relationships between the intensity of cold-air outbreaks and the evolution of synoptic and planetary-scale features over North America. Mon. Wea. Rev., 124, 1067-1083, https://doi.org/10.1175/1520-0493(1996)124<1067: RBTIOC $>2.0 . \mathrm{CO} ; 2$.

— outbreaks over eastern North America. Mon. Wea. Rev., 117, 2687-2700, https://doi.org/10.1175/1520-0493(1989)117<2687: AEOECA $>2.0 . \mathrm{CO} ; 2$.

Lim, Y.-K., and S. D. Schubert, 2011: The impact of ENSO and the Arctic Oscillation on winter temperature extremes in the southeast United States. Geophys. Res. Lett., 38, L15706, https://doi.org/10.1029/2011GL048283.

Loikith, P. C., and A. J. Broccoli, 2012: Characteristics of observed atmospheric circulation patterns associated with temperature extremes over North America. J. Climate, 25, 7266-7281, https://doi.org/10.1175/JCLI-D-11-00709.1.

_ - and _ 2014: The influence of recurrent modes of climate variability on the occurrence of winter and summer extreme temperatures over North America. J. Climate, 27, 1600-1618, https://doi.org/10.1175/JCLI-D-13-00068.1.

_ - B. R. Lintner, and A. Sweeney, 2017: Characterizing largescale meteorological patterns and associated temperature and precipitation extremes over the northwestern United States using self-organizing maps. J. Climate, 30, 2829-2847, https:/ doi.org/10.1175/JCLI-D-16-0670.1.

Madonna, E., H. Wernli, H. Joos, and O. Martius, 2014: Warm conveyor belts in the ERA-Interim dataset (1979-2010). Part I: Climatology and potential vorticity evolution. J. Climate, 27, 3-26, https://doi.org/10.1175/JCLI-D-12-00720.1.

Massacand, A. C., H. Wernli, and H. C. Davies, 2001: Influence of upstream diabatic heating upon an alpine event of heavy precipitation. Mon. Wea. Rev., 129, 2822-2828, https://doi.org/ 10.1175/1520-0493(2001)129<2822:IOUDHU>2.0.CO;2.

Matsueda, S., and Y. Takaya, 2015: Global influence of the MaddenJulian Oscillation on extreme temperature events. J. Climate, 28, 4141-4151, https://doi.org/10.1175/JCLI-D-14-00625.1.

Meehl, G. A., and C. Tebaldi, 2004: More intense, more frequent, and longer lasting heat waves in the 21 st century. Science, $\mathbf{3 0 5}$, 994-997, https://doi.org/10.1126/science.1098704.

,,-- H. Teng, and T. C. Peterson, 2007: Current and future U.S. weather extremes and El Niño. Geophys. Res. Lett., 34, L20704, https://doi.org/10.1029/2007GL031027.

Moore, B. J., 2017: Rossby wave breaking and widespread extreme precipitation events in the central and eastern U.S. Ph.D. dissertation, University at Albany, State University of New York, 188 pp.

, K. M. Mahoney, E. M. Sukovich, R. Cifelli, and T. M. Hamill, 2015: Climatology and environmental characteristics of extreme precipitation events in the southeastern United States. Mon. Wea. Rev., 143, 718-741, https://doi.org/10.1175/ MWR-D-14-00065.1.

Mundhenk, B. D., E. A. Barnes, and E. D. Maloney, 2016: Allseason climatology and variability of atmospheric river frequencies over the North Pacific. J. Climate, 29, 4885-4903, https://doi.org/10.1175/JCLI-D-15-0655.1.

Namias, J., 1978: Multiple causes of the North American abnormal winter 1976-77. Mon. Wea. Rev., 106, 279-295, https://doi.org/ 10.1175/1520-0493(1978)106<0279:MCOTNA > 2.0.CO;2.

Neiman, P. J., F. M. Ralph, G. A. Wick, J. D. Lundquist, and M. D. Dettinger, 2008: Meteorological characteristics and overland precipitation impacts of atmospheric rivers affecting the west coast of North America based on eight years of SSM/I satellite observations. J. Hydrometeor., 9, 22-47, https://doi.org/ 10.1175/2007JHM855.1.

North, G. R., T. L. Bell, R. F. Cahalan, and F. J. Moeng, 1982: Sampling errors in the estimation of empirical orthogonal functions. Mon. Wea. Rev., 110, 699-706, https://doi.org/ 10.1175/1520-0493(1982)110<0699:SEITEO > 2.0.CO;2.

NWS, 2018: NWS weather fatality, injury, and damage statistics. NOAA/NWS, accessed 27 August 2018, http://www.nws.noaa. gov/om/hazstats.shtml.

Peterson, A. G., and J. T. Abatzoglou, 2014: Observed changes in false springs over the contiguous United States. Geophys. Res. Lett., 41, 2156-2162, https://doi.org/10.1002/2014GL059266.

Peterson, T. C., M. P. Hoerling, P. A. Stott, and S. C. Herring, 2013: Explaining extreme events of 2012 from a climate perspective. Bull. Amer. Meteor. Soc., 94, S1-S74, https://doi.org/10.1175/ BAMS-D-13-00085.1.

Pfahl, S., C. Schwierz, M. Croci-Maspoli, C. M. Grams, and H. Wernli, 2015: Importance of latent heat release in ascending air streams for atmospheric blocking. Nat. Geosci., 8 , 610-614, https://doi.org/10.1038/ngeo2487.

Portis, D. H., M. P. Cellitti, W. L. Chapman, and J. E. Walsh, 2006: Low-frequency variability and evolution of North American cold air outbreaks. Mon. Wea. Rev., 134, 579-597, https:// doi.org/10.1175/MWR3083.1.

Ralph, F. M., P. J. Neiman, and G. A. Wick, 2004: Satellite and CALJET aircraft observations of atmospheric rivers over the eastern North Pacific Ocean during the winter of 1997/98. Mon. Wea. Rev., 132, 1721-1745, https://doi.org/10.1175/ 1520-0493(2004)132<1721:SACAOO > 2.0.CO;2.

Rex, D. F., 1950: Blocking action in the middle troposphere and its effect upon regional climate. I: An aerological study of blocking action. Tellus, 2A, 196-211, https://doi.org/10.1111/ j.2153-3490.1950.tb00331.x.

Riemer, M., S. C. Jones, and C. A. Davis, 2008: The impact of extratropical transition on the downstream flow: An idealized modelling study with a straight jet. Quart. J. Roy. Meteor. Soc., 134, 69-91, https://doi.org/10.1002/qj.189.

Rogers, J. C., and R. V. Rohli, 1991: Florida citrus freezes and polar anticyclones in the Great Plains. J. Climate, 4, 1103-1113, https:// doi.org/10.1175/1520-0442(1991)004<1103:FCFAPA > 2.0.CO;2.

Roundy, P. E., N. Sakaeda, K. MacRitchie, and L. Gloeckler, 2017: Weather-climate interactions and MJO influences. Climate Extremes: Patterns and Mechanisms, S.-Y. S. Wang et al., Eds., Amer. Geophys. Union, 139-163, https://doi.org/10.1002/ 9781119068020.ch9. 
Saha, S., and Coauthors, 2010: The NCEP Climate Forecast System Reanalysis. Bull. Amer. Meteor. Soc., 91, 1015-1057, https:// doi.org/10.1175/2010BAMS3001.1.

— , and Coauthors, 2014: The NCEP Climate Forecast System version 2. J. Climate, 27, 2185-2208, https://doi.org/10.1175/ JCLI-D-12-00823.1.

Sanders, F., and J. R. Gyakum, 1980: Synoptic-dynamic climatology of the "bomb." Mon. Wea. Rev., 108, 1589-1606, https://doi.org/ 10.1175/1520-0493(1980)108<1589:SDCOT>2.0.CO;2.

Scherer, M., and N. S. Diffenbaugh, 2014: Transient twenty-first century changes in daily-scale temperature extremes in the United States. Climate Dyn., 42, 1383-1404, https://doi.org/ 10.1007/s00382-013-1829-2.

Thompson, D. W. J., and J. M. Wallace, 1998: The Arctic oscillation signature in wintertime geopotential height and temperature fields. Geophys. Res. Lett., 25, 1297-1300, https://doi.org/ 10.1029/98GL00950.

Tippett, M. K., J. T. Allen, V. A. Gensini, and H. E. Brooks, 2015: Climate and hazardous convective weather. Curr. Climate Change Rep., 1, 60-73, https://doi.org/10.1007/ s40641-015-0006-6.

Torn, R. D., 2010: Diagnosis of the downstream ridging associated with extratropical transition using short-term ensemble forecasts. J. Atmos. Sci., 67, 817-833, https://doi.org/10.1175/ 2009JAS3093.1.

- , and G. J. Hakim, 2015: Comparison of wave packets associated with extratropical transition and winter cyclones. Mon. Wea. Rev., 143, 1782-1803, https://doi.org/10.1175/ MWR-D-14-00006.1.

Turner, J. K., and J. R. Gyakum, 2011: The development of arctic air masses in northwest Canada and their behavior in a warming climate. J. Climate, 24, 4618-4633, https://doi.org/ 10.1175/2011JCLI3855.1.

UCAR, 2018: NCEP Climate Forecast System Version 2 (CFSv2) selected hourly time-series products. Frequently asked questions about CFS V2, https://rda.ucar.edu/datasets/ds094.1/ \#docs/FAQs_hrly_timeseries.html.

Vavrus, S., J. E. Walsh, W. L. Chapman, and D. Portis, 2006: The behavior of extreme cold air outbreaks under greenhouse warming. Int. J. Climatol., 26, 1133-1147, https://doi.org/ 10.1002/joc.1301.
Walsh, J. E., A. S. Phillips, D. H. Portis, and W. L. Chapman, 2001: Extreme cold outbreaks in the United States and Europe, 1948-99. J. Climate, 14, 2642-2658, https://doi.org/10.1175/ 1520-0442(2001)014<2642:ECOITU >2.0.CO;2.

Westby, R. M., and R. X. Black, 2015: Development of anomalous temperature regimes over the southeastern United States: Synoptic behavior and role of low-frequency modes. Wea. Forecasting, 30, 553-570, https://doi.org/10.1175/WAF-D-14-00093.1.

_- Y.-Y. Lee, and R. X. Black, 2013: Anomalous temperature regimes during the cool season: Long-term trends, lowfrequency mode modulation, and representation in CMIP5 simulations. J. Climate, 26, 9061-9076, https://doi.org/10.1175/ JCLI-D-13-00003.1.

Wheeler, M. C., and H. H. Hendon, 2004: An all-season real-time multivariate MJO index: Development of an index for monitoring and prediction. Mon. Wea. Rev., 132, 1917-1932, https:// doi.org/10.1175/1520-0493(2004)132<1917:AARMMI>2.0.CO;2.

Wilks, D. S., 2011: Statistical Methods in the Atmospheric Sciences. 3rd ed. Elsevier, 676 pp.

Winters, A. C., D. Keyser, and L. F. Bosart, 2019: The development of the North Pacific jet phase diagram as an objective tool to monitor the state and forecast skill of the upper-tropospheric flow pattern. Wea. Forecasting, 34, 199-219, https://doi.org/ 10.1175/WAF-D-18-0106.1.

Wolter, K., M. Hoerling, J. K. Eischeid, G. J. van Oldenborgh, X.-W. Quan, J. E. Walsh, T. N. Chase, and R. M. Dole, 2015: How unusual was the cold winter of $2013 / 14$ in the Upper Midwest? Bull. Amer. Meteor. Soc., 96, S10-S14, https:// doi.org/10.1175/BAMS-D-15-00126.1.

Xie, Z., R. X. Black, and Y. Deng, 2017: Daily-scale planetary wave patterns and the modulation of cold season weather in the northern extratropics. J. Geophys. Res. Atmos., 122, 8383 8398, https://doi.org/10.1002/2017JD026768.

Zhang, C., 2016: MJO and extreme weather/climate events. $D y$ namics and Predictability of Large-Scale, High-Impact Weather and Climate Events, J. Li et al., Eds., Cambridge University Press, 294-300, https://doi.org/10.1017/CBO9781107775541.025.

Zhu, Y., and R. E. Newell, 1998: A proposed algorithm for moisture fluxes from atmospheric rivers. Mon. Wea. Rev., 126, 725-735, https://doi.org/10.1175/1520-0493(1998)126<0725: APAFMF $>2.0 . \mathrm{CO} ; 2$. 